\title{
HUMAN PERIODONTAL LIGAMENT STEM CELLS CULTURED ONTO CORTICO-CANCELLOUS SCAFFOLD DRIVE BONE REGENERATIVE PROCESS
}

\author{
F. Diomede ${ }^{1,2}$, N. Zini ${ }^{3,4}$, V. Gatta ${ }^{5}$, S. Fulle ${ }^{6}$, I. Merciaro ${ }^{1,2}$, M. D’Aurora ${ }^{5}$, R.M.L. La Rovere ${ }^{6}$, T. Traini ${ }^{1}$, \\ J. Pizzicannella ${ }^{1,7}$, P. Ballerini ${ }^{5}$, S. Caputi ${ }^{1}$, A. Piattelli ${ }^{1}$ and O. Trubiani ${ }^{1,2 *}$ \\ ${ }^{1}$ Department of Medical, Oral and Biotechnological Sciences, University “G. d'Annunzio”, Chieti-Pescara, \\ Chieti, Italy. \\ ${ }^{2}$ Laboratory of Stem Cells and Regenerative Medicine, University “G. d'Annunzio”, Chieti-Pescara, Chieti, Italy. \\ ${ }^{3} \mathrm{CNR}$ - National Research Council of Italy, IGM, Bologna, Italy. \\ ${ }^{4} \mathrm{SC}$ Laboratory of Musculosckeletal Cell Biology, IOR, Bologna, Italy. \\ ${ }^{5}$ Department of Psychological, Health and Territorial Sciences, University “G. d'Annunzio” Chieti-Pescara, \\ Chieti, Italy. \\ ${ }^{6}$ Department of Neuroscience, Imaging and Clinical Sciences, University “G. d'Annunzio", Chieti-Pescara, Chieti, Italy \\ ${ }^{7}$ ASL02 Lanciano-Vasto-Chieti, Ospedale "San Pio", Vasto (CH), Italy.
}

\begin{abstract}
The purpose of this work was to test, in vitro and in vivo, a new tissue-engineered construct constituted by porcine cortico-cancellous scaffold (Osteobiol Dual Block) (DB) and xeno-free ex vivo culture of human Periodontal Ligament Stem Cells (hPDLSCs). hPDLSCs cultured in xeno-free media formulation preserved the stem cells' morphological features, the expression of stemness and pluripotency markers, and their ability to differentiate into mesenchymal lineage. Transmission electron microscopy analysis suggested that after one week of culture, both noninduced and osteogenic differentiation induced cells joined and grew on DB secreting extracellular matrix (ECM) that in osteogenic induced samples was hierarchically assembled in fibrils. Quantitative RT-PCR (qRT-PCR) showed the upregulation of key genes involved in the bone differentiation pathway in both differentiated and undifferentiated hPDLSCs cultured with DB (hPDLSCs/DB). Functional studies revealed a significant increased response of calcium transients in the presence of DB, both in undifferentiated and differentiated cells stimulated with calcitonin and parathormone, suggesting that the biomaterial could drive the osteogenic differentiation process of hPDLSCs. These data were confirmed by the increase of gene expression of L-type voltage-dependent $\mathrm{Ca}^{2+}\left(\mathrm{VDCC}_{\mathrm{L}}\right)$, subunits $\alpha 1 \mathrm{C}$ and $\alpha 2 \mathrm{D} 1$ in undifferentiated cells in the presence of DB. In vivo implantation of the hPDLSCs/DB living construct in the mouse calvaria evidenced a precocious osteointegration and vascularisation process. Our results suggest consideration of $\mathrm{DB}$ as a biocompatible, osteoinductive and osteoconductive biomaterial, making it a promising tool to regulate cell activities in biological environments and for a potential use in the development of new custom-made tissue engineering.
\end{abstract}

Keywords: Stem cells - osteogenesis, dental tissue (periodontal ligament), biomaterials - scaffolds, dental - regenerative repair, tissue engineering/regenerative medicine, biomaterials - biocompatibility (in vivo).
*Address for correspondence:

Trubiani Oriana, MD,

Department of Medical, Oral and Biotechnological Sciences,

University “G. d'Annunzio" Chieti-Pescara,

Via dei Vestini 31, 66100 Chieti, Italy

Telephone number: +3908713554097

Email: trubiani@unich.it

\section{Introduction}

Many patients worldwide suffer from bone disease or bone defects such as osteoporosis, bone fractures, skeletal cancer. In order to solve the problem of lost bone tissue, a major emphasis of bone tissue engineering is on tissue regeneration rather than tissue replacement. Bone tissue engineering requires a mechanically competent osteoconductive/inductive construct that guarantees the cell attachment, the maintenance of cell properties and their differentiation into osteogenic lineage (Rose and Oreffo, 2002). To this aim, new therapies in the context of bone regeneration provide the use of living constructs that possess the high potential and capacity to integrate with the surrounding tissue. Cellular components and an appropriate $3 \mathrm{D}$ scaffold represent a critical factor in tissue engineering, which requires in vitro and in vivo assays before the use in clinical practice.

The scaffolds need to support various cellular processes and functions, including cell colonisation, migration, growth and differentiation. Autologous bone grafting is the gold standard for the treatment of extensive osseous defects; however, the procedure is associated with potential donor-site morbidity, for example: neurovascular injury, fracture, infection and prolonged pain.

In addition, the quantity of autologous bone is limited in a given individual (Zwingenberger et al., 2014), thus the allogenic biomaterial showing the same structural features could be a suitable alternative. Osteobiol Dual Block (DB) is a collagenated porcine block that keeps intact cancellous and cortical bone structure and, for its rigid consistency, the original volume of grafting site can be preserved making it an ideal scaffold for bone reconstructions (Manescu et al., 2016). 
Mesenchymal Stem Cells (MSCs) are adult stem cells that have a wide distribution in several adult tissues, including those of dental origin (Egusa et al., 2012) and they are able to give rise to multiple specialised cell types.

Although many stem cells sources are available in the oral cavity, our research is focused on the periodontal ligament as the gold standard adult MSC source. The human periodontal ligament stem cells (hPDLSCs) can even be isolated from human periodontium using a minimally invasive periodontal access flap surgery in healthy donors (Diomede et al., 2014; Trubiani et al., 2008b). hPDLSCs have demonstrated the ability to regenerate periodontal tissues such as cementum, periodontal ligament and alveolar bone in experimental animal models (Seo et al., 2005).

We recently reported that expanded hPDLSCs using xeno-free media formulation provide the basis for Good Manufacturing Practice. They preserved: i) the stem cells morphological features and karyotype, ii) the expression of stemness and pluripotency markers, iii) the ability to differentiate into mesenchymal lineage (Trubiani et al., 2015). Indeed, xeno-free standardised protocols for hPDLSCs, encourage the large clinical-scale production of functionally competent stem cells. In the present study, we monitored the morphological features of hPDLSCs, cultured in the presence of a 3D-DB scaffold, in terms of morphological and functional features. Moreover, the in vivo studies with hPDLSCs/DB scaffold were also carried out to clarify whether the presence of stem cells could potentiate the regenerative performance of the scaffold perse.

\section{Materials and Methods}

\section{Scaffold material}

The scaffold material is OsteoBiol ${ }^{\circledR}$ Dual-Block (Tecnoss ${ }^{\circledR}$ Dental, Coazze (TO), Italy). It is a collagenated porcine block constituted by natural cancellous and cortical bone. The peculiarity is represented by the cortical bone which is naturally anchored to cancellous bone in order to provide stability after grafting. This scaffold guarantees, due to its rigid consistency, that the original volume of the grafting site can be preserved. It is indicated for horizontal crest reconstructions. Porcine derived blocks $(20 \times 15 \mathrm{~mm})$ were cut into slices at a thickness of approximately $5 \mathrm{~mm}$, using a Buehler low-speed saw equipped with a diamond water blade (Buehler Isomet, Lake Bluff, IL, USA). The slices were processed through washes in distilled water $\left(\mathrm{d}-\mathrm{H}_{2} \mathrm{O}\right)$, sonicated for $1 \mathrm{~min}$ ( 1 cycle $70 \mathrm{~W}$, SONOPULS, HD2070, Bandelin; Berlin, Germany) and then further washed with sterile PBS (LiStarFish, Milan, Italy).

\section{Cell culture}

Written approval for the human periodontal ligament collection performed in this study was obtained from the Medical Ethics Committee at the Medical School, "G. d'Annunzio" University, Chieti, Italy (n 266/17.04.14, Principal Investigator: Trubiani Oriana), and written informed consent for clinical research and for the processing of personal data was obtained from each participant (range age 20-35 years). The Department of Medical, Oral and Biotechnological Sciences and the Laboratory of Stem Cells and Regenerative Medicine are certified according to the quality standard ISO 9001:2008 RINA (certificate no. 32031/15/S).

Five human periodontal ligament biopsies from five different patients were carried out from human premolar teeth, scheduled to be removed for orthodontic purposes on healthy volunteers. All periodontal ligament biopsies were de-identified. Each patient was prepared for surgery by pretreatment for one week with professional dental hygiene and during the surgery by decontamination of the oral cavity with chlorhexidine. The periodontal ligament tissue was collected after tooth extraction. Explants were obtained from alveolar crest and horizontal fibres of the periodontal ligament by scraping the roots of non-carious molar teeth with a Gracey's curette (Carranza, 1996). The specimens of periodontal tissue were ground and then washed several time with PBS (LiStarFish, Milan, Italy), subsequently cultured using TheraPEAK ${ }^{\text {TM} M S C G M-C D ~}{ }^{\text {TM }}$ BulletKit serum free, chemically defined (MSCGM-CD) medium for the growth of human MSCs (Lonza, Basel, Switzerland) in order to minimise the exposure to substances of non-human origin. The medium was changed twice a week, and cells spontaneously migrating from the explant fragments after reaching about $80 \%$ of confluence, were trypsinised Triple Select (LiStar Fish), subsequently split and subcultured. Cells utilised for the experimental assays were at the $2^{\text {nd }}$ passage.

For in vivo experiments hPDLSCs were labelled for $30 \mathrm{~min}$ with the red fluorescent lipophilic dye, PKH26 (Sigma-Aldrich, Milan, Italy), according to manufacturer's instructions. PKH26 is stably incorporated in lipid regions of the cell membrane allowing in vivo cell tracking and monitoring studies. The PKH26-labeled hPDLSCs $\left(2 \times 10^{6}\right)$ were seeded on DB and then incubated for $2 \mathrm{~d}$ at $37{ }^{\circ} \mathrm{C}$ in $5 \% \mathrm{CO}_{2}$ and air before to be implanted in the mouse calvaria (see below).

\section{Cytofluorimetric assay}

Antibodies: fluorescein isothiocyanate-conjugated antiCD13 (CD13 FITC), phycoerythrin-conjugated anti-CD29 (CD29 PE), FITC-conjugated: anti-CD44 (CD44 FITC), anti-CD45 (CD45 FITC), anti-CD105 (CD105 FITC) and anti-CD166 (CD166 FITC) were obtained from Ancell (MN, USA); FITC-conjugated anti-CD14 (CD14 FITC) and PE-conjugated anti-CD133 (CD133 PE) were purchased from Milteny Biotec (Bergisch Gladbach, Germany); PE-conjugated anti-CD73 (CD73 PE), FITCconjugated anti-CD90 (CD90 FITC), allophycocyaninconjugated anti-CD117 (CD117-APC), PE-conjugated anti-CD146 (CD146 PE), PE-conjugated anti-CD271 (CD271-PE), Alexa488-conjugated anti-Sox2 (Sox2 Alexa488), FITC-conjugated anti-SSEA4 (SSEA4 FITC), Alexa488-conjugated anti-HLA-ABC (HLA-ABC Alexa488), PE-conjugated anti-HLA-DR (HLA-DR PE) and PE-conjugated anti-OCT3/4 (OCT3/4 PE) obtained from Becton Dickinson (BD, San Jose, CA, USA); FITCconjugated anti-CD144 (CD144-FITC) was obtained from Acris Antibodies (Herford, Germany); PE-conjugated anti-CD34 (CD34-PE) was purchased from Beckman 
Coulter (Fullerton, CA, USA); appropriate secondary FITC-conjugated antibody was obtained from Jackson Immunoresearch Laboratories (West Grove, PA, USA).

Washing buffer (phosphate buffered saline, PBS, $0.1 \%$ sodium azide and $0.5 \%$ bovine serum albumin, BSA) was used for all washing steps ( $3 \mathrm{~mL}$ of washing buffer and centrifugation, $400 \times \mathrm{g} 8 \mathrm{~min}$ at $4^{\circ} \mathrm{C}$ ). Briefly, $5 \times 10^{5}$ cells/sample were incubated with $100 \mu \mathrm{L}$ of $20 \mathrm{mM}$ ethylenediaminetetraacetic acid (EDTA) at $37^{\circ} \mathrm{C}$ for 10 min and washed.

Staining of surface antigens and intracellular antigens was carried out according to Eleuterio et al. (Eleuterio et al., 2013). Quality control included regular check-up with Rainbow Calibration Particles (BD Biosciences). Debris was excluded from the analysis by gating on morphological parameters; 20,000 non-debris events in the morphological gate were recorded for each sample. To assess non-specific fluorescence we used specific irrelevant controls. All antibodies were titrated under assay conditions and optimal photomultiplier (PMT) gains were established for each channel. Data were analysed using FlowJo ${ }^{\text {TM }}$ software (TreeStar, Ashland, OR, USA). Mean Fluorescence Intensity Ratio (MFI Ratio) was calculated dividing the MFI of positive events by the MFI of negative events (Eleuterio et al., 2013).

\section{Cell proliferation and viability assay}

Ex vivo expanded hPDLSCs were seeded at $1 \times 10^{3}$ cells/ well in triplicate using a 96-well flat-bottom plate and cultured in control and in osteogenic medium (see below) in presence or not of DB for 24, 48, $72 \mathrm{~h}$ and 1 week. After the incubation period, $15 \mu \mathrm{L} /$ well of MTT were added to culture medium and cells were incubated for $3 \mathrm{~h}$ at $37^{\circ} \mathrm{C}$. The supernatants were read at $650 \mathrm{~nm}$ wavelength using a microplate reader (Synergy HT, BioTek Instruments, Vermont, USA).

\section{Osteogenic differentiation}

For osteogenesis induction, the primary cells at $2^{\text {nd }}$ passage were seeded at $7.5 \times 10^{3}$ cells $/ \mathrm{cm}^{2}$ in MSCGM-CD culture medium (control medium) in presence or not of $\mathrm{DB}$ and maintained in culture at $37^{\circ} \mathrm{C}$, in a humidified $5 \% \mathrm{CO}_{2}$ atmosphere. At subconfluence, cells were incubated with MSCGM-CD medium with the addition of osteogenic supplements, i.e. $100 \mathrm{nM}$ dexamethasone (Applichem GmbH, Darmstadt, Germany), $10 \mathrm{nM} \beta$-glycerol-phosphate (Applichem) and $0.05 \mathrm{mM}$ 2-phosphate-ascorbic acid (Sigma-Aldrich) (osteoinductive medium) for 1, 2 and 3 weeks (Salvade et al., 2007). Control samples were incubated with MSCBM-CD.

Visualisation of calcium deposition and extracellular matrix mineralisation was obtained by Alizarin Red $\mathrm{S}$ (ARS) staining assay performed after 1, 2 and 3 weeks. According to Gregory et al. (Gregory et al., 2004) cells were washed with PBS, fixed in $10 \%(\mathrm{v} / \mathrm{v})$ formaldehyde (Sigma-Aldrich) for $30 \mathrm{~min}$ and washed twice with abundant $\mathrm{dH}_{2} \mathrm{O}$ prior to addition $0.5 \%$ Alizarin red $\mathrm{S}$ in $\mathrm{H}_{2} \mathrm{O}, \mathrm{pH} 4.0$, for $1 \mathrm{~h}$ at room temperature.

After cell incubation under gentle shaking, cells were washed with $\mathrm{dH}_{2} \mathrm{O}$ four times for $5 \mathrm{~min}$. For staining quantification, $800 \mu \mathrm{L} 10 \%$ (v/v) acetic acid was added to each well. Cells were incubated for 30 min with shaking, and then scraped from the plate, transferred into a $1.5 \mathrm{~mL}$ vial and vortexed for $30 \mathrm{~s}$. The obtained suspension, overlaid with $500 \mu \mathrm{L}$ mineral oil (Sigma-Aldrich), was heated to $85^{\circ} \mathrm{C}$ for $10 \mathrm{~min}$, then transferred to ice for $5 \mathrm{~min}$, carefully avoiding opening of the tubes until fully cooled, and centrifuged at $20,000 \times g$ for $15 \mathrm{~min}$. $500 \mu \mathrm{L}$ of the supernatant were placed into a new $1.5 \mathrm{~mL}$ vial and $200 \mu \mathrm{L}$ of $10 \%(\mathrm{v} / \mathrm{v})$ ammonium hydroxide was added ( $\mathrm{pH} 4.1-\mathrm{pH} 4.5$ ). $150 \mu \mathrm{L}$ of the supernatant obtained from differentiated and undifferentiated hPDLSCs cultured in the presence and in the absence of biomaterial were read in triplicate at $405 \mathrm{~nm}$ by a spectrophotometer (Synergy HT).

\section{Light and transmission electron microscopy}

Glass-adherent hPDLSCs at the $2^{\text {nd }}$ passage and scaffolds processed in the presence and absence of cells, were analysed for morphological evaluation.

$7.5 \times 10^{3}$ cells $/ \mathrm{cm}^{2}$ were seeded on the scaffold and cultured for $7 \mathrm{~d}$ in control and in osteogenic medium. The samples were fixed in $2.5 \%$ glutaraldehyde in $0.1 \mathrm{M}$ cacodylate buffer $\mathrm{pH} 7.4$ for $5 \mathrm{~h}$, post-fixed with $1 \%$ osmium tetroxide, dehydrated in a graded series of ethanol and embedded in Epon. Cross-sections of each scaffold were cut to allow internal analysis. Semi-thin sections were stained with toluidine blue and used for light microscopy. The sections were observed with a Zeiss Axiophot apparatus (Zeiss, Jena, Germany), and images were captured using a Digital Sight, Nikon digital camera. Thin sections were stained with uranyl acetate and lead citrate, and observed with a Zeiss EM 109 electron microscope. Images were captured using a Nikon Dmx 1200F digital camera and ACT-1 software.

\section{RNA extraction and TaqMan quantitative real-time PCR}

Total RNA was extracted from 1 and 3 week differentiated and undifferentiated hPDLSCs, cultured in the presence or not of the DB biomaterial using the RNeasy Mini Kit (Quiagen, Hilden, Germany). $6 \mu \mathrm{g}$ of RNA from each sample were reverse transcribed using the High Capacity RNA-to-cDNA Kit (Applied Biosystems, Foster, UK). Quantitative Real-Time was performed on a 96-well TaqMan $^{\circledR}$ Array Human Osteogenesis following the manufacturer's instructions, and run on an Abi 7900HT Sequencing Detection System (Applied Biosystems). The plate contains 92 assays related to the osteogenic differentiation, including transcription and growth factors genes involved in the physiological processes of bone and tooth formation, mineralisation and maintenance. The amplification cycle was $10 \mathrm{~min}$ at $95^{\circ} \mathrm{C}$, followed by 40 cycles of $15 \mathrm{~s}$ at $95^{\circ} \mathrm{C}$ and $1 \mathrm{~min}$ at $60^{\circ} \mathrm{C}$. Three independent experiments were run for each condition for a total of 12 plates. Real-Time data were analysed by DataAssist software (Applied Biosystems). A global normalisation analysis was used and GAPDH, $18 \mathrm{~s}$ and HPRT1 were chosen as selected internal controls. Only genes showing no outlier replicates and a maximum $\mathrm{Ct}$ value $=35$ were included in the analysis. A gene was considered differentially expressed if showing a fold 
change $>1.4$ or $<0.7$ and a $p$-value $<0.05 ; p$-values were adjusted using Benjamini-Hochberg FDR. Ingenuity Pathways Analysis (IPA) software (Ingenuity Systems, Redwood City, CA, USA) was employed to infer biological functions and networks of the selected gene datasets. IPA predicts functional networks based on known gene functional interactions and ranks them by a significance score.

For the calcium channel analysis, total RNA was extracted from 1 and 3 week differentiated and undifferentiated hPDLSCs cultured in presence or in absence of DB, using the Total RNA Purification Kit (Norgen Biotek corp., Ontario, CA, USA) according to the manufacturer's directions. Complementary DNA (cDNA) synthesis was obtained the M-MLV Reverse Transcriptase reagents (Applied Biosystems, Forster City, CA, USA). Real-Time PCR was carried out with the MasterCycler ep realplx real-time PCR system (Eppendorf, Hamburg, Germany). L-Type voltage-dependent $\mathrm{Ca}^{2+}$ channels, $\alpha 1 \mathrm{C}$ (CACNA1C) and $\alpha 2 \mathrm{D} 1$ (CACNA2D1) subunits, were evaluated. Commercially available TaqMan Gene Expression Assay ( $\alpha 1 \mathrm{C}:$ NM_001167624; $\alpha 2:$ NM_000722) and TaqMan Universal PCR Master Mix (Applied Biosystems, Foster City, CA) were used according to the standard protocols. Beta-2 microglobulin (B2M: Hs $00984230 \mathrm{~m} 1$ ) (Applied Biosystems) was used for template normalisation. qRT-PCR was performed in three independent experiments and triplicate determinations were carried out for each sample.

\section{Western blotting}

Thirty $\mu \mathrm{g}$ of proteins obtained by differentiated and undifferentiated hPDLSCs, seeded on the 3D scaffold after $7 \mathrm{~d}$ of culture, were separated on SDS-PAGE and subsequently transferred to PVDF membrane using a TRANS blotting apparatus. Membranes were saturated for $2 \mathrm{~h}$ at $37^{\circ} \mathrm{C}$ in blocking buffer $(1 \times \mathrm{PBS}, 5 \%$ milk, $0.1 \%$ Tween-20), then incubated overnight at $4^{\circ} \mathrm{C}$ in blocking buffer containing mouse primary antibodies anti-RUNX2, BMP $2 / 4$, Collagen 1 , and $\beta$-actin (all from Santa Cruz, CA) diluted 1:200 respectively. After four washes in PBS containing $0.1 \%$ Tween-20, samples were incubated for $1 \mathrm{~h}$ at room temperature with peroxidase-conjugated secondary antibody anti-mouse diluted $1: 2,000$ in $1 \times$ PBS, $3 \%$ milk, $0.1 \%$ Tween. PVDF membrane were visualised using the enhancing chemiluminescence detection system (ECL) (Amersham Pharmacia Biotech, PA, USA) with photo documenter Alliance 4.7 (Uvitec, Cambridge, UK) (Trubiani et al., 2016b). The signals were captured by ECL enhancing and analysed using UVIband-1D gel analysis (Uvitec).

\section{Intracellular calcium experiments}

hPDLSCs were seeded in 96-well plates at confluence of $3 \times 10^{3}$ cells/well and cultured for 3 weeks in the presence or not of biomaterial. The cells, loaded with Fura-2 AM, were sequentially excited at 340 or $380 \mathrm{~nm}$ with a highspeed wavelength switcher Polychrome II (Till Photonics, Germany). Fluorescence images were collected using a $40 \times$ oil objective lens, acquired using an intensified CCD camera (Hamamatsu Photonics, Hamamatsu), stored on a
PC, and analysed off-line. The acquisition time for each fluorescence emission was $0.5 \mathrm{~s}$. The ratio of fluorescence signal into the ROI has been taken into consideration after the subtraction of background fluorescence. The 340 and $380 \mathrm{~nm}$ traces and 340/380-ratio were recorded and analysed using Aquacosmos software (Hamamatsu). The loading protocol of the calcium indicator was performed using $5 \mu \mathrm{M}$ of fluorescent probe in normal external solution (NES) supplemented with $10 \mathrm{mg} / \mathrm{mL}$ of BSA for $40 \mathrm{~min}$ at $37^{\circ} \mathrm{C}$ and $5 \% \mathrm{CO}_{2}$. NES is composed by $10 \mathrm{mM}$ glucose, $140 \mathrm{mM} \mathrm{NaCl}, 2.8 \mathrm{mM} \mathrm{KCl}, 2 \mathrm{mM} \mathrm{CaCl}, 2 \mathrm{mM} \mathrm{MgCl}$, and $10 \mathrm{mM}$ HEPES, pH 7.4, 290-300 mOsM. After loading, the cells were rinsed and maintained in NES for $10 \mathrm{~min}$ at room temperature (RT), to allow the de-esterification of the probe. Changes in free cytosolic calcium were monitored in response to $50 \mathrm{nM}$ of human Parathyroid Hormone (PTH) exposure or $10 \mathrm{nM}$ human Calcitonin (CT).

\section{Animal surgery}

Five male adult C57BL/6 mice (Harlan Nossan, Milan, Italy) $20-25 \mathrm{~g}$ weight were used. Mice were housed in a controlled environment and provided with standard rodent chow and water. Animal care was in compliance with Italian regulations on protection of animals used for experimental and other scientific purpose (D.M. 116/92) as well as with the EEC regulations (O.J. of E.C. L 358/1 12/18/1986). Written approval for the animal experiments in this study was obtained from the Medical and Animal Ethical Committee of Italian National Institute of Health in agreement with D.lgs 26/2014. Experimental procedures did not cause any significant animal suffering. Mice were anaesthetised using chloral hydrate $(40 \mu \mathrm{g} / \mathrm{kg}$ body weight).

$2 \times 10^{6}$ hPDLSCs PKH26-stained /DB construct and $\mathrm{DB}$ were implanted in the mouse calvaria. For their texture and flexibility, the scaffolds were easily inserted in contact to bone tissue after scraping with scalpel the cortical calvaria bone tissue. After 3 weeks, the animals were scarified and their calvariae were processed for morphological analysis.

\section{Histological processing}

The specimens were fixed for $72 \mathrm{~h}$ in $10 \%$ formalin solution, dehydrated in ascending graded alcohols and embedded in LR White resin (Sigma-Aldrich). After polymerisation, undecalcified oriented cut sections of $50 \mu \mathrm{m}$ were prepared and ground down to about $30 \mu \mathrm{m}$ by using the TT System (TMA2, Grottammare, Italy). The sections were analysed with the confocal Laser Scanning Microscopy Zeiss LSM510 META (Zeiss) and after stained with a solution of acid fucsin and methylene blue (Trubiani et al., 2016a). The investigation was carried out by means of a bright-field light microscope (Leica Microsystem, Milan, Italy) connected to a high-resolution digital camera DFC425B Leica (Leica Microsystem). Three dimensional reconstruction has been obtained by means ZEN2 software (Zeiss).

\section{Data and statistical analysis}

The Statistical Package for Social Science (SPSS, v.21.0, Inc. Chicago, IL, USA) was used for data analysis. 


\begin{tabular}{|c|c|c|}
\hline A & Oct $3 / 4$ & $97.2 \% \pm 1.2 \%$ \\
\hline \multirow[t]{2}{*}{ Stemness markers } & Sox-2 & $98.4 \% \pm 1.1 \%$ \\
\hline & SSEA-4 & $95.4 \% \pm 2.4 \%$ \\
\hline \multirow{5}{*}{ MSC markers } & CD 29 & $97.6 \% \pm 1.8 \%$ \\
\hline & CD 44 & $98.2 \% \pm 2.1 \%$ \\
\hline & CD 73 & $96.3 \% \pm 1.4 \%$ \\
\hline & CD 90 & $95.1 \% \pm 2.3 \%$ \\
\hline & CD 105 & $97.4 \% \pm 2.3 \%$ \\
\hline \multirow{3}{*}{$\begin{array}{l}\text { Haematopoietic } \\
\text { markers }\end{array}$} & CD 14 & - \\
\hline & CD 34 & - \\
\hline & CD 45 & - \\
\hline
\end{tabular}

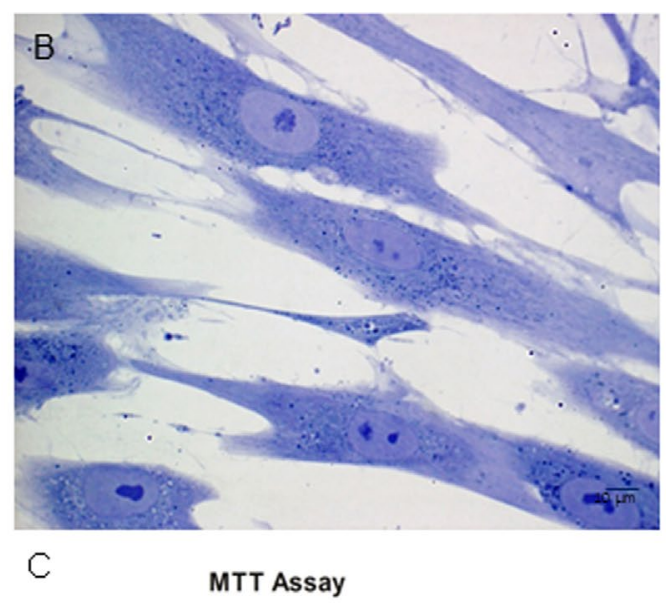

Fig. 1. Flow cytometry analysis. (A) hPDLSCs are positive for stemness and mesenchymal markers (Oct $3 / 4$, Sox2, SSEA-4, CD29, CD44, CD73, CD90, CD105) and negative for haematopoietic markers (CD14, CD34, CD45). (B) Light microscopy image represents cell culture stained with toluidine blue. hPDLSCs showed a homogeneous fibroblast-like morphology with spindle-shaped appearance and long cytoplasmic processes. Nuclei appeared as round or oval, with one or more nucleoli (Mag.: $\times 40)$. (C) MTT assay is representative of five separate experiments performed using cells at $2^{\text {nd }}$ passage. Cell proliferation analysis of hPDLSCs cultured with and without DB scaffold under basal and osteogenic conditions. The average of three separate experiments of the measured optical density (OD) is shown.

Parametrical methods were used after having verified the existence of the required assumptions. In particular, the normality of the distribution and the equality of variances were assessed by the Shapiro-Wilk and Levene's tests, respectively. The factors under investigation were the time elapsed, the presence of DB and the osteogenic condition for MTT assay. Data were expressed as means and standard deviation of the recorded optical density values. The differences among the levels of the factors under investigation were evaluated performing two-way-ANOVA tests. Tukey's test was applied for pairwise comparisons. A value of $p<0.05$ was considered statistically significant.

\section{Results}

\section{Flow cytometry analysis}

The expression of surface molecules (CD29+, CD44+, $\mathrm{CD} 105+, \mathrm{CD} 73+, \mathrm{CD} 90+)$ and of pluripotency associated markers (OCT3/4+, SSEA-4+, SOX-2+) were evident in xeno-free cultured hPDLSCs. The cells were negative for the following markers: CD14, CD34, and CD45 (Fig. 1A). Statistical flow cytometry analysis of five different biological samples are reported.

\section{hPDLSC morphological analyses}

Toluidine blue stained primary cultures of hPDLSCs were analysed at the second passage. Cells adherent to glass coverslips showed a spindle-shaped appearance with long cytoplasmic processes (Fig. 1B).

\section{Cell growth}

MTT assay was performed at indicated time points (24, 48, $72 \mathrm{~h}$ and 1 week) to measure the viability and proliferation rate of stem cell population seeded in control and in osteogenic condition in the presence or in the absence of DB. The assay displayed an increasing trend in the proliferation rate for all the examined time points. Each test was repeated three times for each cell population (Fig. 1C).

\section{Light and transmission electron microscopy}

Bone scaffold pieces were analysed by light microscopy. Toluidine blue-stained semi-thin sections showed that they consisted of compact and trabecular bone (Fig. 2A,B). The two areas presented both demineralised and mineralised zones. The first stained in blue while the latter was more transparent.

We also evaluated the cell distribution and organisation within the bone scaffold at 1 week in control and in the osteogenic medium growth condition.

Light microscopy analysis showed that the cells were uniformly distributed in close relationship with the scaffold in the compact zone, while the cells colonised the biomaterial, filling the empty spaces among the trabeculae in the medulla area in all the samples examined. After 1 week of culture in control medium, cells were organised 


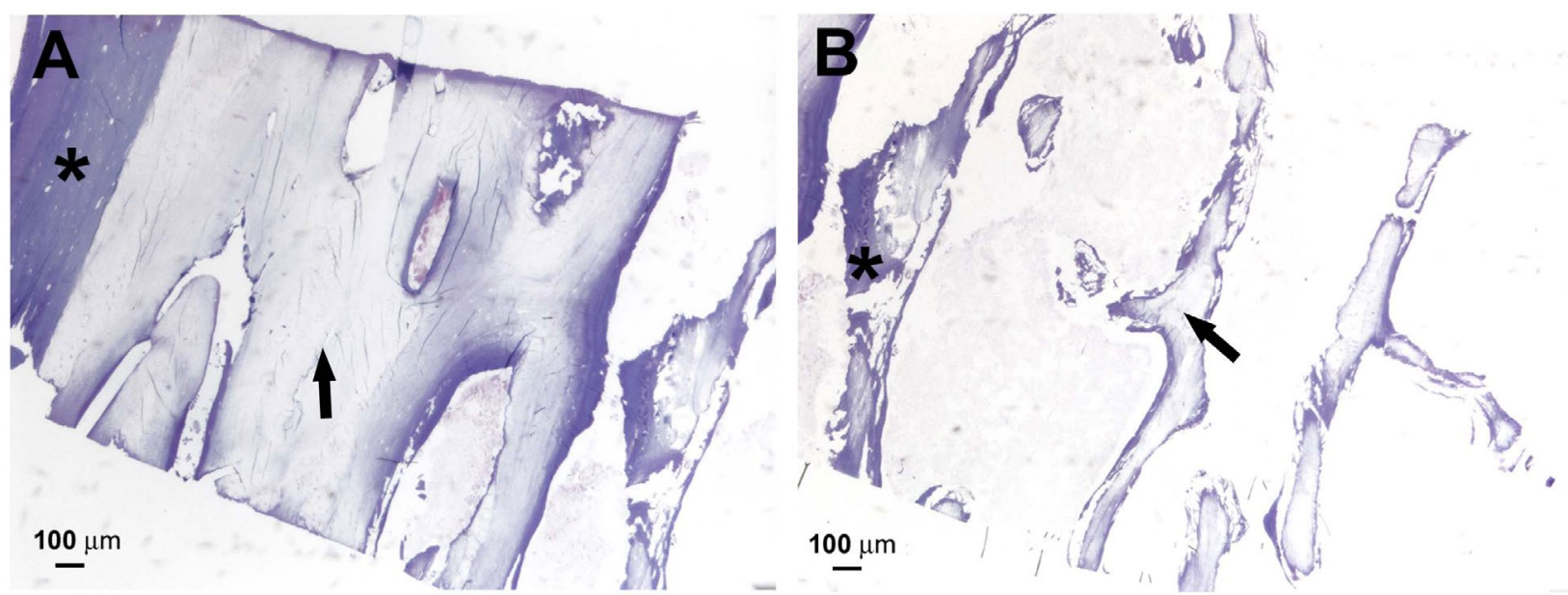

Fig. 2. Light microscopy analysis. Semi-thin sections of the scaffold were stained with toluidine blue solution. The sections show the compact area in (A) and the contiguous trabecular zone in $(\mathbf{B})$ of the same sample. The two areas presented both demineralised (asterisks) and mineralised zones (arrows). Scale bars: $100 \mu \mathrm{m}$.

in two or three layers in the compact area (Fig. 3A,B), while the cells penetrated colonising the spaces among the trabeculae in trabecular area (Fig. 3E,F); the layers increased in compact area and numerous cells were present among trabeculae in the osteogenic condition (Fig. $4 \mathbf{A}, \mathbf{B}, \mathbf{E}, \mathbf{F})$. At ultrastructural level, the cells appeared elongated or ovoid with euchromatic nuclei, mitochondria, lysosomal bodies, and rough endoplasmic reticulum (RER) profiles (Fig. 3C,D,G,H; Fig. 4C,D,G,H). Electron microscopy observation indicated that hPDLSCs were able to produce, particularly among the cells, extracellular matrix (ECM), which appeared organised in cross-banded fibrils in the samples grown in osteogenic medium (Fig. $4 \mathbf{D}, \mathbf{H})$ with respect to control cells where they were not visible (Fig. 3D,H). Some junctional-like contacts were observed between cells grown in the osteogenic condition (Fig. 4D inset,H). No difference was observed between de-mineralised and mineralised areas.

\section{Osteogenic gene modulation}

In order to verify the DB biomaterial capability to induce the osteogenic differentiation of hPDLSCs we performed a transcriptome analysis comparing the gene expression profile of undifferentiated cells cultured with the 3D-biomaterial ( 1 and 3 weeks) versus undifferentiated cells cultured without the 3D-biomaterial ( 1 and 3 weeks) and the differentiated cells cultured in the presence of the biomaterial ( 1 and 3 weeks) versus the differentiated cells cultured in the absence of the biomaterial ( 1 and 3 weeks). Quantitative Real Time-PCR of a 92 osteogenesis-related assay panel was employed to evidence the biomaterial modulation of the hPDLSCs gene expression profile. After 1 week, the undifferentiated hPDLSCs cultured in the presence of DB revealed the statistically significant upregulation of 27 genes (blue bars) and the down-regulation of 11 genes (blue bars), when compared to undifferentiated cells cultured without the biomaterial (red bars) (Fig 5A). The analysis of differentiated cells in the presence of the biomaterial (blue bars) versus differentiated cells without biomaterial (red bars) unrevealed the significantly up and down-expression of 41 and 7 transcripts respectively
(Fig. 5B). After 3 weeks, the undifferentiated hPDLSCs cultured in the presence of DB revealed the statistically significant up-regulation of 43 genes (blue bars) and the down-regulation of 12 genes (blue bars) (Fig. 7A), when compared to undifferentiated cells cultured without the biomaterial (red bars). The analysis of the differentiated cells in the presence of the biomaterial (blue bars) versus the differentiated cells without biomaterial unrevealed the significantly up and down-expression of 26 and 17 transcripts respectively (Fig. 7,B). IPA functional analysis of the gene datasets in undifferentiated (Figs. 6A \& 8A) and in differentiated cells (Figs. 6C \& 8C) showed the involvement of specific biological functions related to connective tissue development, bone formation and cellular growth. IPA network analysis generated a top network for each dataset (Figs. 6B,D \& 8B,D). These data showed that the biomaterial caused, in all the examined conditions, the up-regulation of osteogenic-related transcripts such as the BMP family several collagens, in particular COL1A1, MSX1 and RUNX2. Moreover, the biomaterial in the undifferentiated cells modulated the expression of key genes involved in the osteogenic differentiation pathway such as RUNX2, collagens and SMADs.

\section{Osteogenic differentiation}

The osteogenic differentiation process induced in primary cultures after 1, 2 and 3 weeks was evaluated by ARS staining fluorimetric detection (Fig. 9A). Differentiation induction was evident in cells seeded on DB cultured with control and osteoinductive medium (Fig. 9B), showing the scaffold ability to induce the formation of nodules of mineralised matrix and calcium deposition.

\section{Protein level of osteogenic related markers}

In differentiated and undifferentiated samples seeded with the biomaterial after $7 \mathrm{~d}$ of culture the image analysis of the western blot specific bands showed a modulation of all bone tissue-specific proteins examined. In particular, RUNX2, BMP2/4, and collagen type I were detected, displaying an evident osteogenic phenotype maturation of hPDLSCs (Fig. 9C-F). 

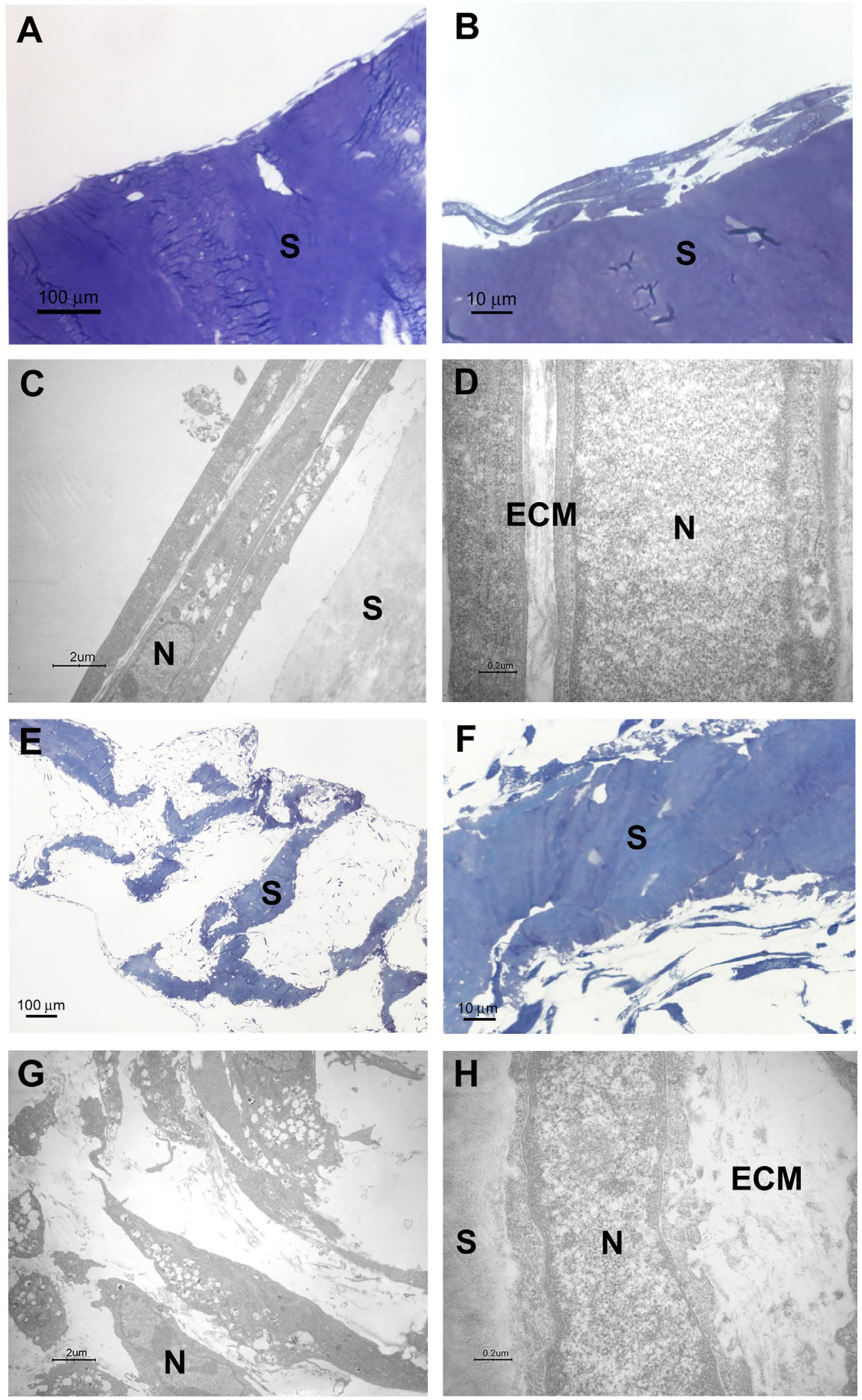

Fig. 3. Light and transmission electron microscopy analysis. Cells seeded on bone scaffold (S) were analysed after 1 week of culture in the control medium. Sections were cut perpendicularly to the surface of seeding. (A-D) Compact zone. (A,B) Light microscopy of toluidine blue-stained semi-thin section at different magnifications. (C,D) Transmission electron microscopy of thin sections at different magnifications. Some cells appear elongated while others show ovoid shape with short elongation. The nuclei $(\mathrm{N})$ appear euchromatic and extracellular matrix (ECM) is mainly present among cells. (E-H) Trabecular zone. (E,F) Light microscopy of toluidine blue-stained semi-thin section at different magnifications. $(\mathbf{G}, \mathbf{H})$ Transmission electron microscopy of thin sections of different zone. (G) Area among the trabeculae, $(\mathbf{H})$ area close to a trabecular surface. The cells appear to be elongated or ovoid with euchromatic nuclei (N) and extracellular matrix (ECM) is also mainly present among cells. Scale bars: $(\mathbf{A}, \mathbf{E}) 100 \mu \mathrm{m} ;(\mathbf{B}, \mathbf{F}) 10 \mu \mathrm{m} ;(\mathbf{C}, \mathbf{G}) 2 \mu \mathrm{m} ;(\mathbf{D}, \mathbf{H}) 0.2 \mu \mathrm{m}$. 

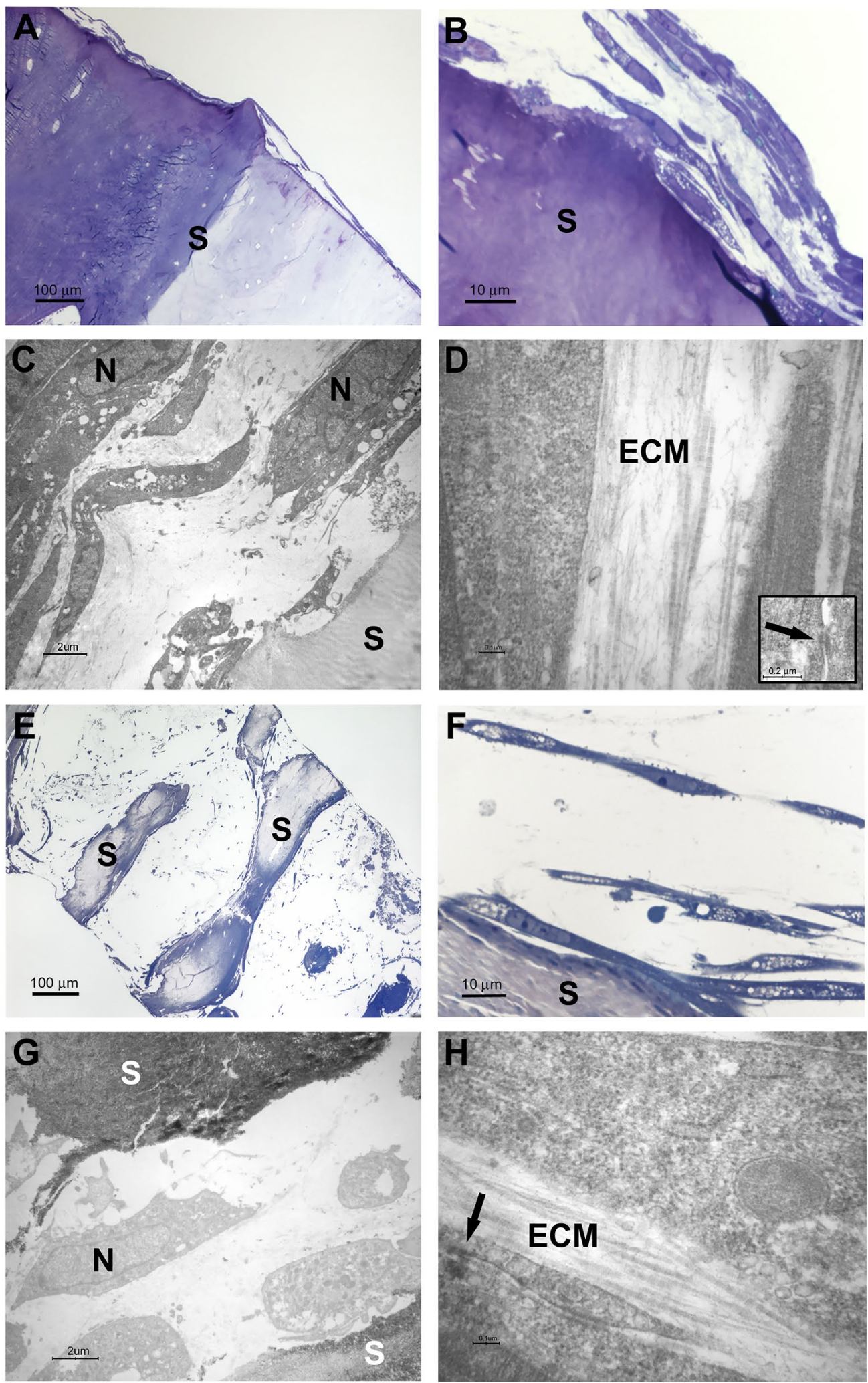

Fig. 4. Light and transmission electron microscopy analysis. Cells seeded on bone scaffold (S) were analysed after 1 week of culture in the osteogenic medium. Sections were cut perpendicularly to the surface of seeding. (A-D) Compact zone. (A,B) Light microscopy of toluidine blue-stained semi-thin section at different magnifications. (C,D) Transmission electron microscopy of thin sections at different magnifications. (C) Elongated and ovoid cells with euchromatic nuclei (N) are organised in different layers on the scaffold. (D) Extracellular matrix (ECM) is organised in cross-banded fibrils and mainly present among the cells. Junctional-like contacts are observed between cells (inset, arrow). (E-H) Trabecular zone. (E,F) Light microscopy of toluidine blue-stained semi-thin section at different magnifications. $(\mathbf{G}, \mathbf{H})$ Transmission electron microscopy of thin sections at different magnifications. (G) Elongated and ovoid cells with euchromatic nuclei $(\mathrm{N})$ are present in between trabeculae. $(\mathbf{H})$ Extracellular matrix (ECM), showing cross-banded fibrils is mainly present among cells. Junctional-like contacts can be observed between cells (arrow). Scale bars: (A,E) $100 \mu \mathrm{m} ;(\mathbf{B}, \mathbf{F}) 10 \mu \mathrm{m}$; (C,G) $2 \mu \mathrm{m}$; (D,H) $0.1 \mu \mathrm{m}$; (D inset) $0.2 \mu \mathrm{m}$. 
A

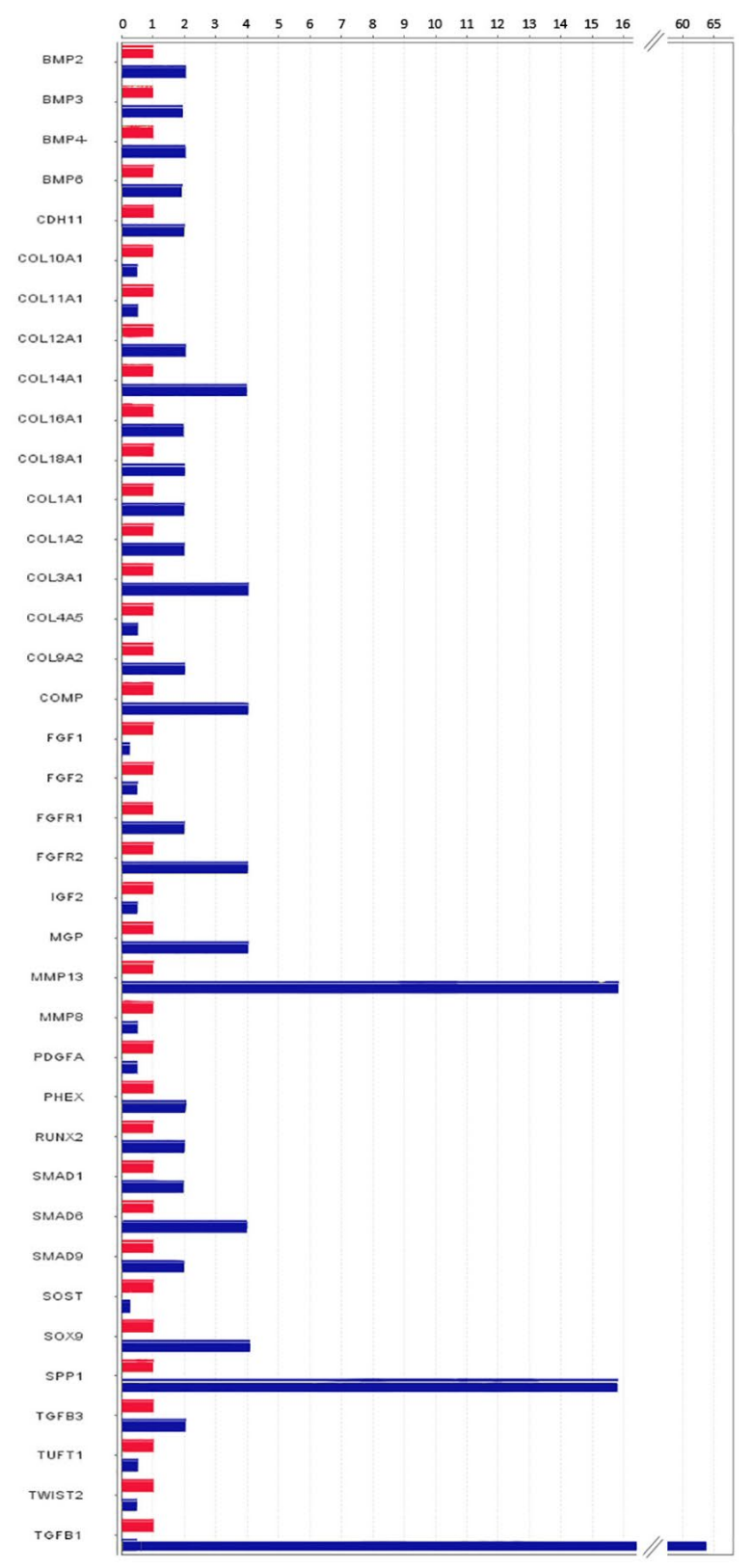

\section{B}

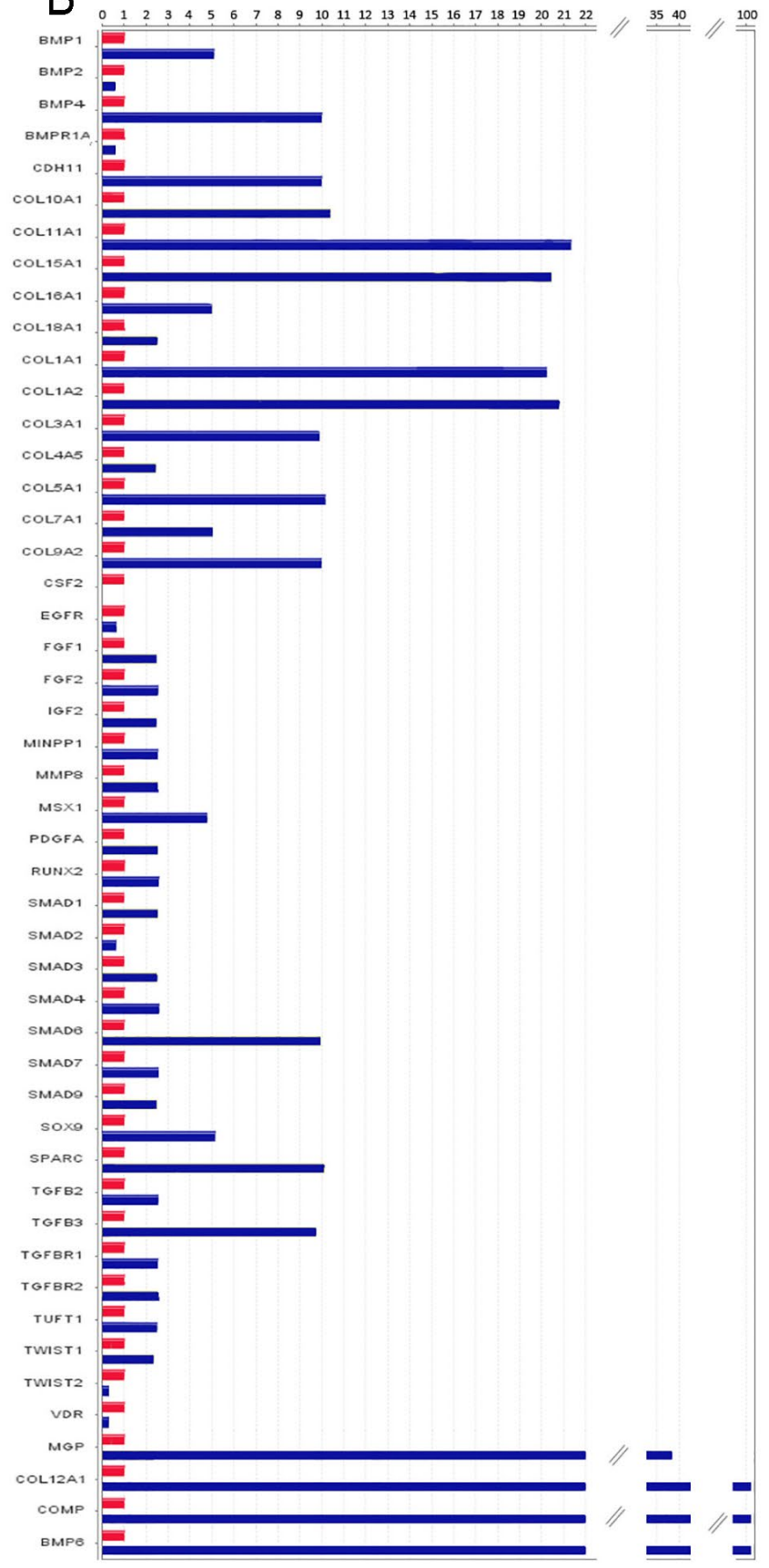

Fig. 5. Osteogenic-related genes expression analysis. Bar charts show the significant relative expression of the analysed genes in undifferentiated and differentiated hPDLSCs after 1 week of culture in presence of DB. (A) Bar charts show the significant relative expression of genes in undifferentiated hPDLSCs after 1 week of culture with biomaterial versus undifferentiated hPDLSCs after 1 week of culture without biomaterial, indicating that biomaterial is able to induce the differentiation. (B) Bar charts show the significant relative expression of genes in differentiated hPDLSCs after 1 week of culture with biomaterial versus differentiated hPDLSCs after 1 week of culture without biomaterial, indicating that the biomaterial seems to strengthen the expression of essential genes to osteo-differentiation. In blue and red is labelled the gene expression in cells cultured with and without DB respectively. 
A

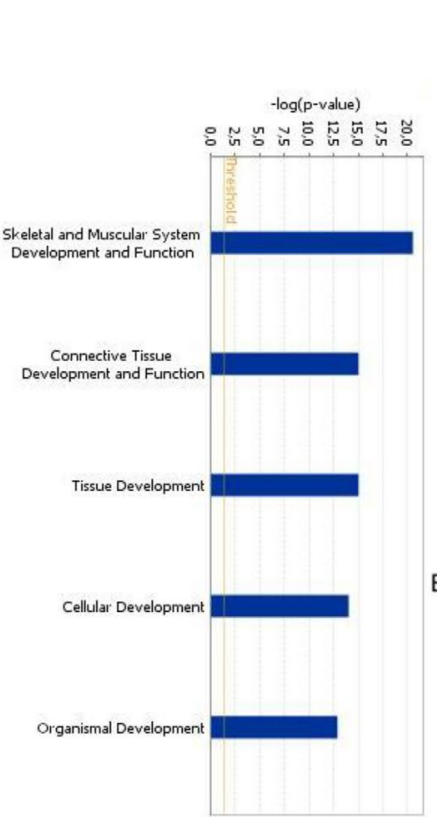

C

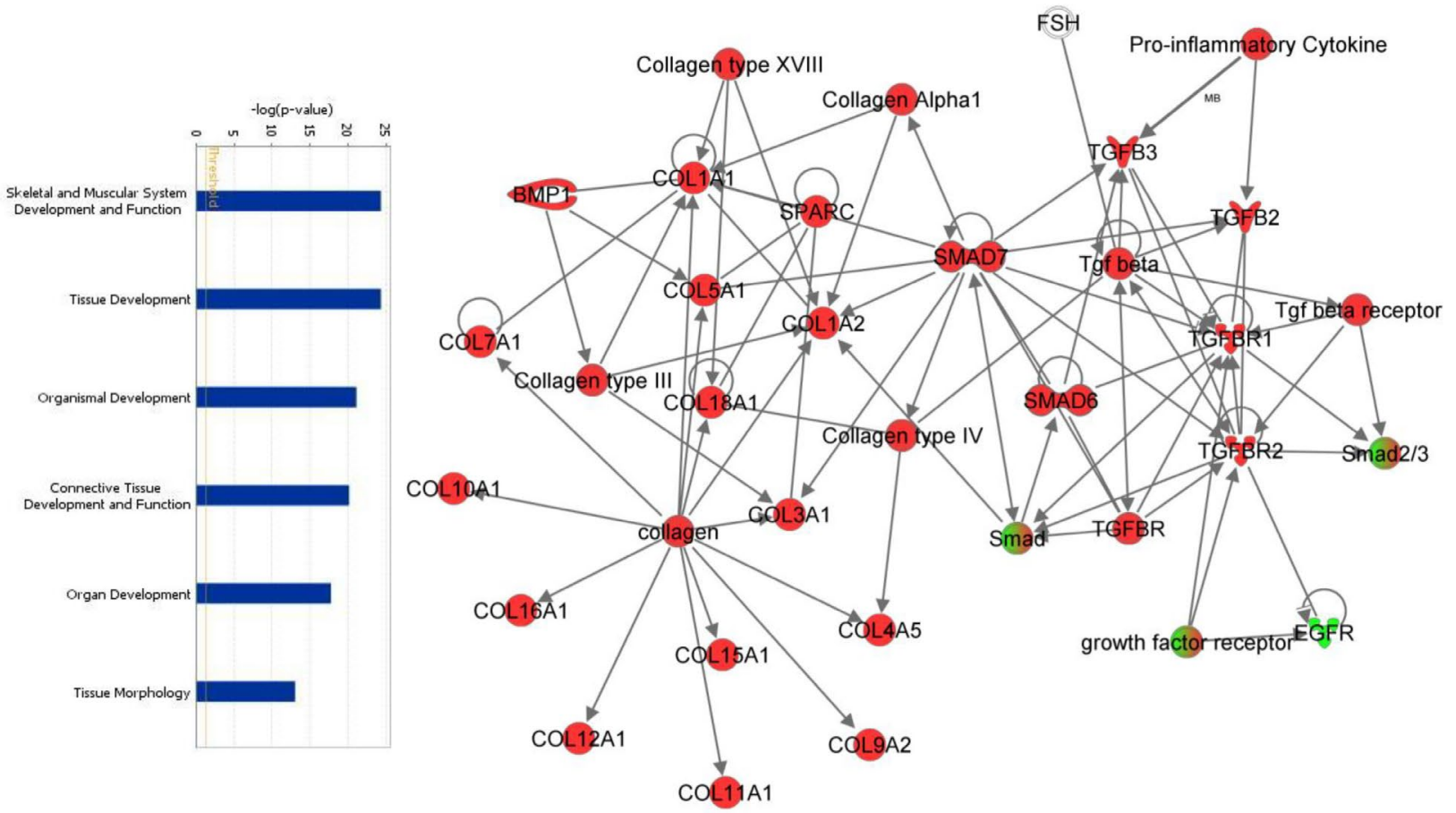

B

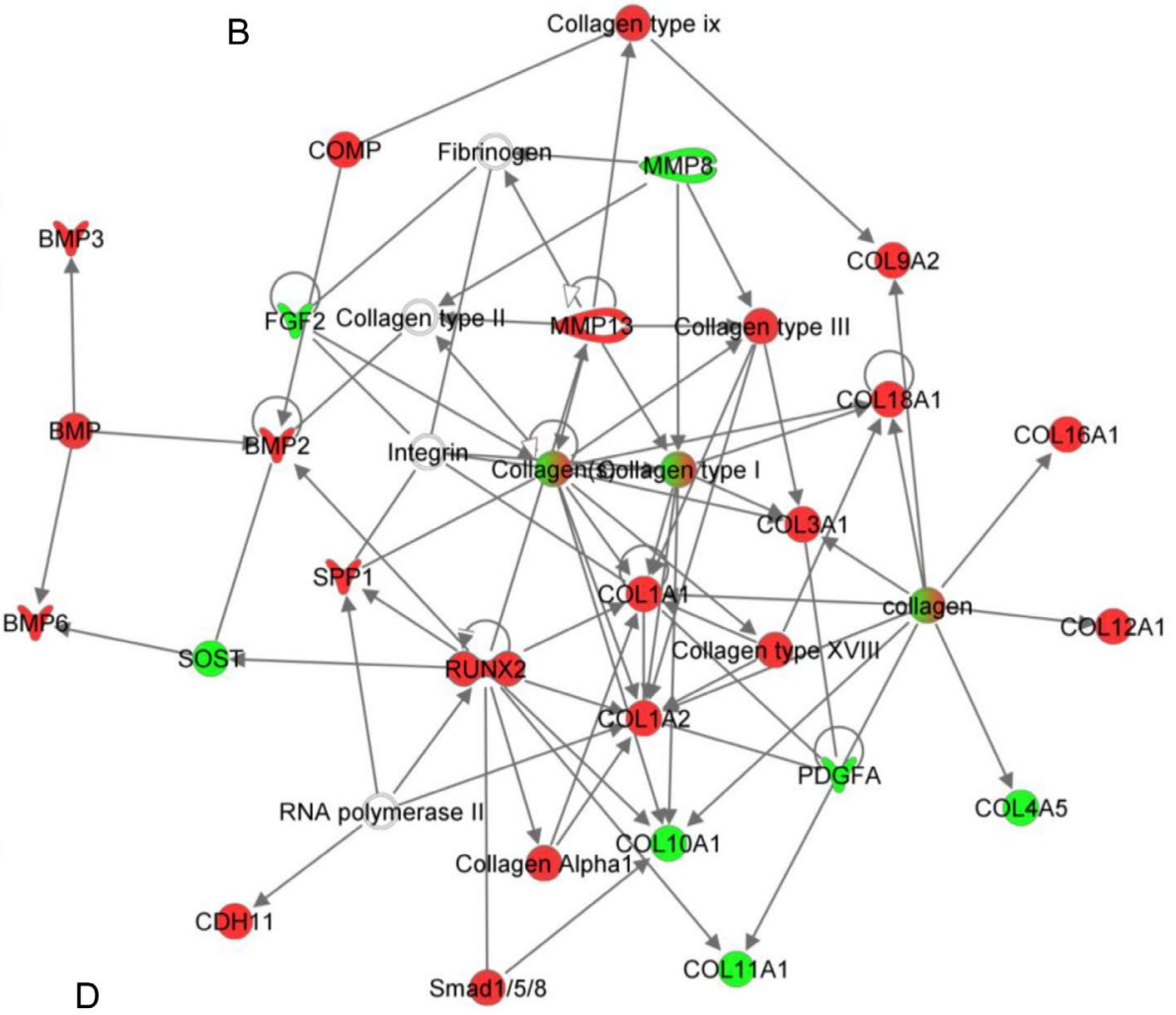

ix 
A

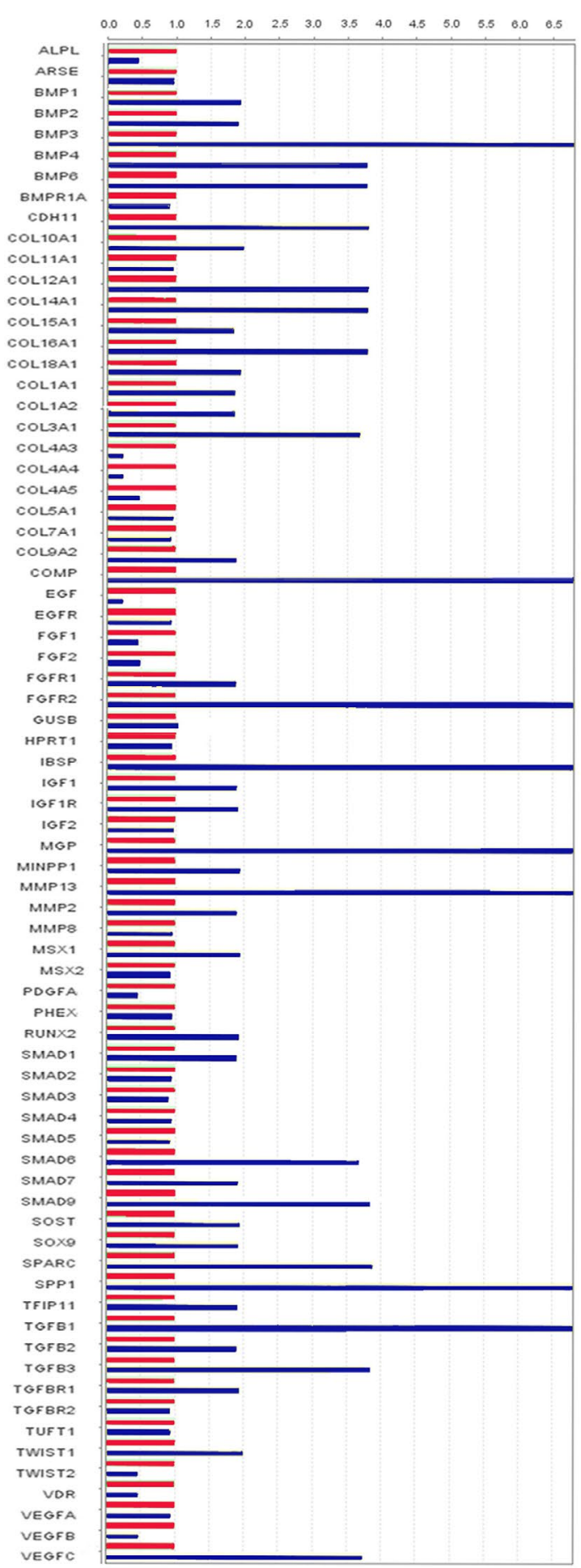

B

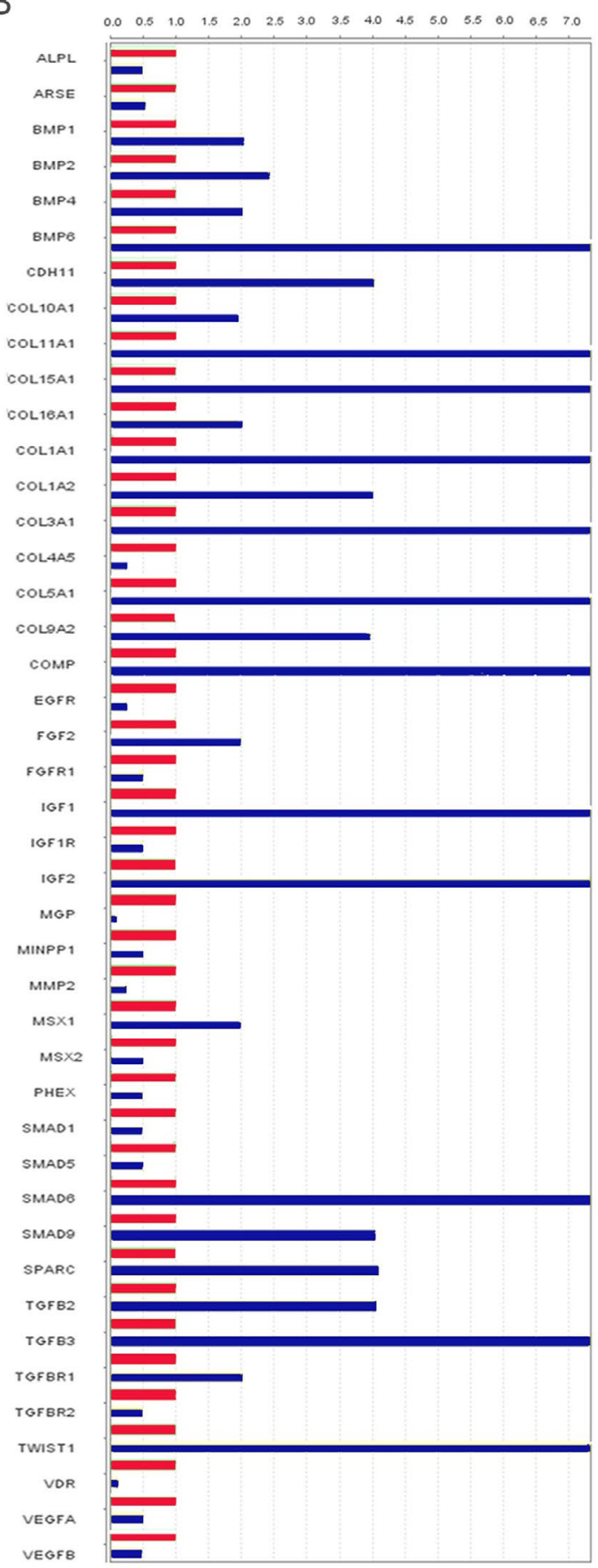

Fig. 7. Osteogenic-related genes expression analysis. Bar charts show the significant relative expression of the analysed genes in undifferentiated and differentiated hPDLSCs after 3 weeks of culture in presence of DB. (A) Bar charts show the significant relative expression of genes in undifferentiated hPDLSCs after 3 weeks of culture with biomaterial versus undifferentiated hPDLSCs after 3 weeks of culture without biomaterial, indicating that biomaterial is able to induce the differentiation. (B) Bar charts show the significant relative expression of genes in differentiated hPDLSCs after 3 weeks of culture with biomaterial versus differentiated hPDLSCs after 3 weeks of culture without biomaterial, indicating that the biomaterial seems to strengthen the expression of essential genes to osteo-differentiation. In blue and red is labelled the gene expression in cells cultured with and without DB respectively. 
A

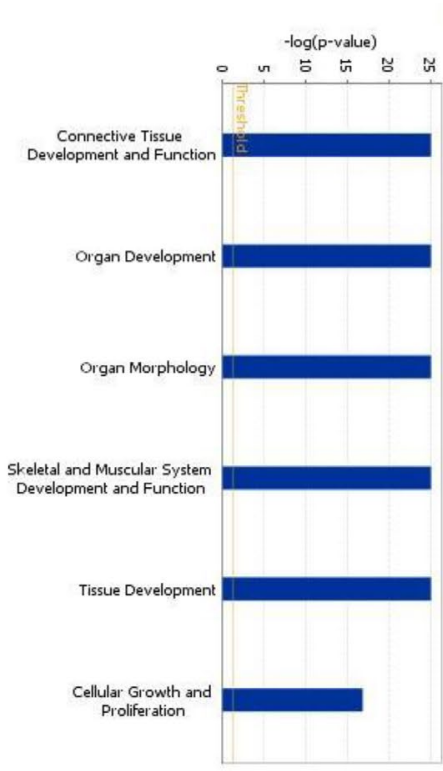

C

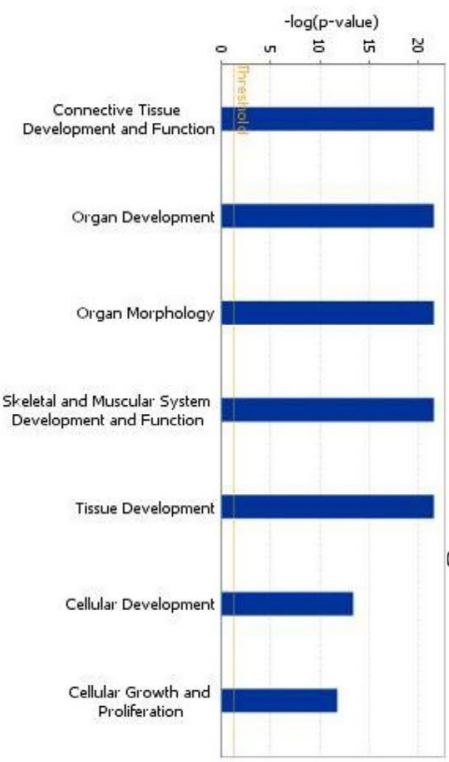

B

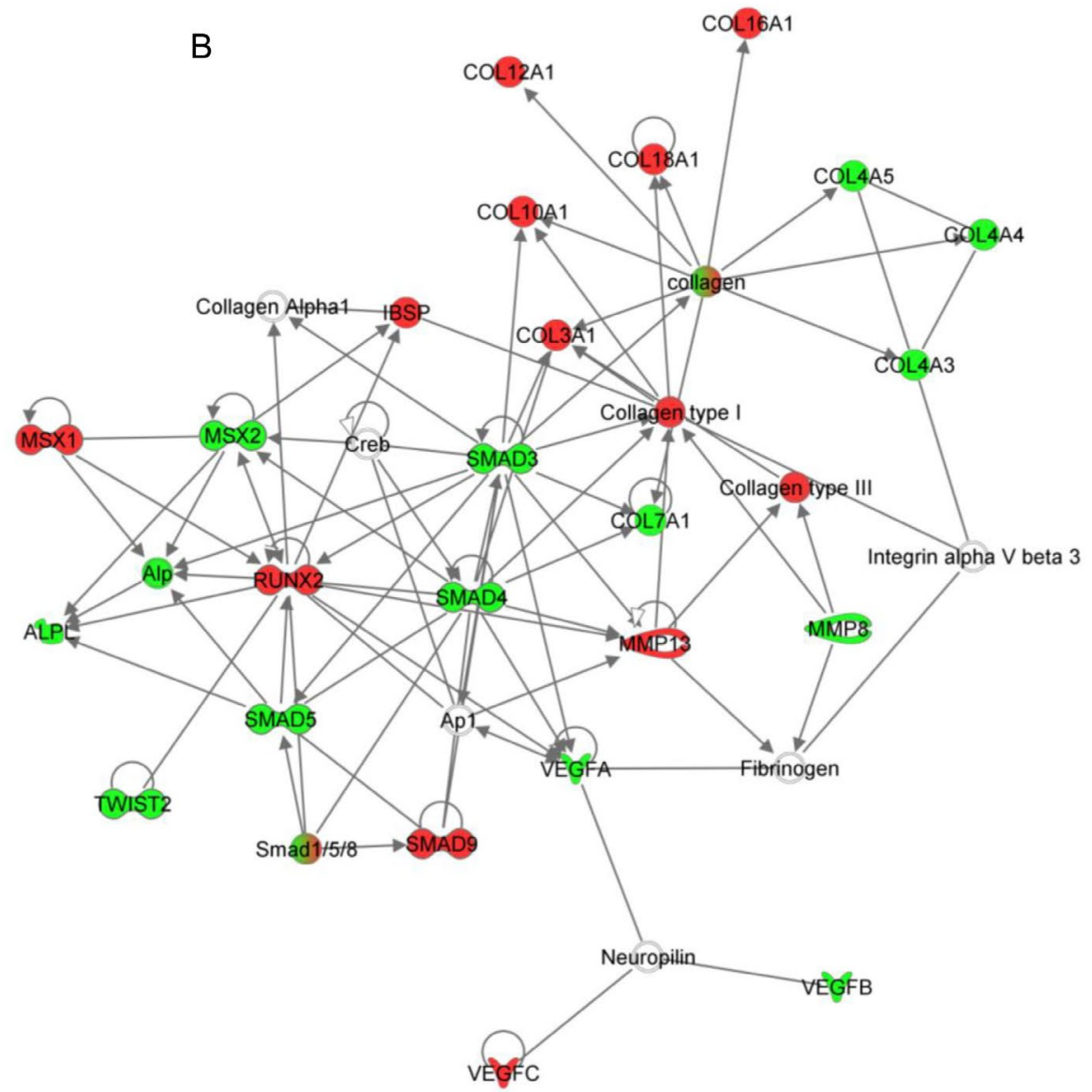

D

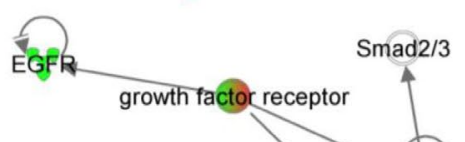

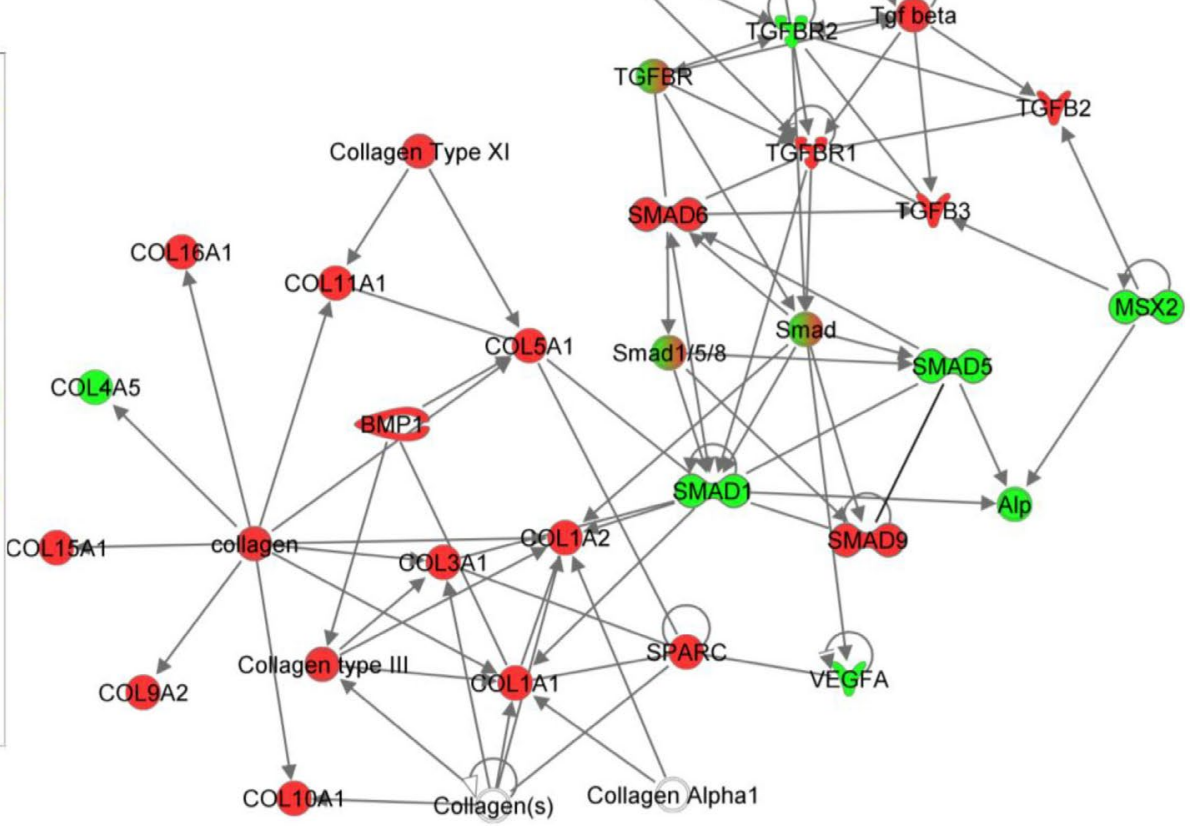

Fig. 8. IPA biological function analysis of the analysed genes. (A,B) IPA biological functions of the significantly expressed genes in undifferentiated hPDLSCs after 3 weeks of culture with biomaterial versus undifferentiated hPDLSCs after 3 weeks of culture without biomaterial. IPA-inferred top network showing that the biomaterial induces the expression of key genes involved in the osteogenic differentiation. (C,D) IPA biological functions of the significantly expressed genes in differentiated hPDLSCs after 3 weeks of culture with 3D scaffold versus differentiated hPDLSCs after 3 weeks of culture without biomaterial. IPA-inferred top network showing the over-expression of many collagens. 


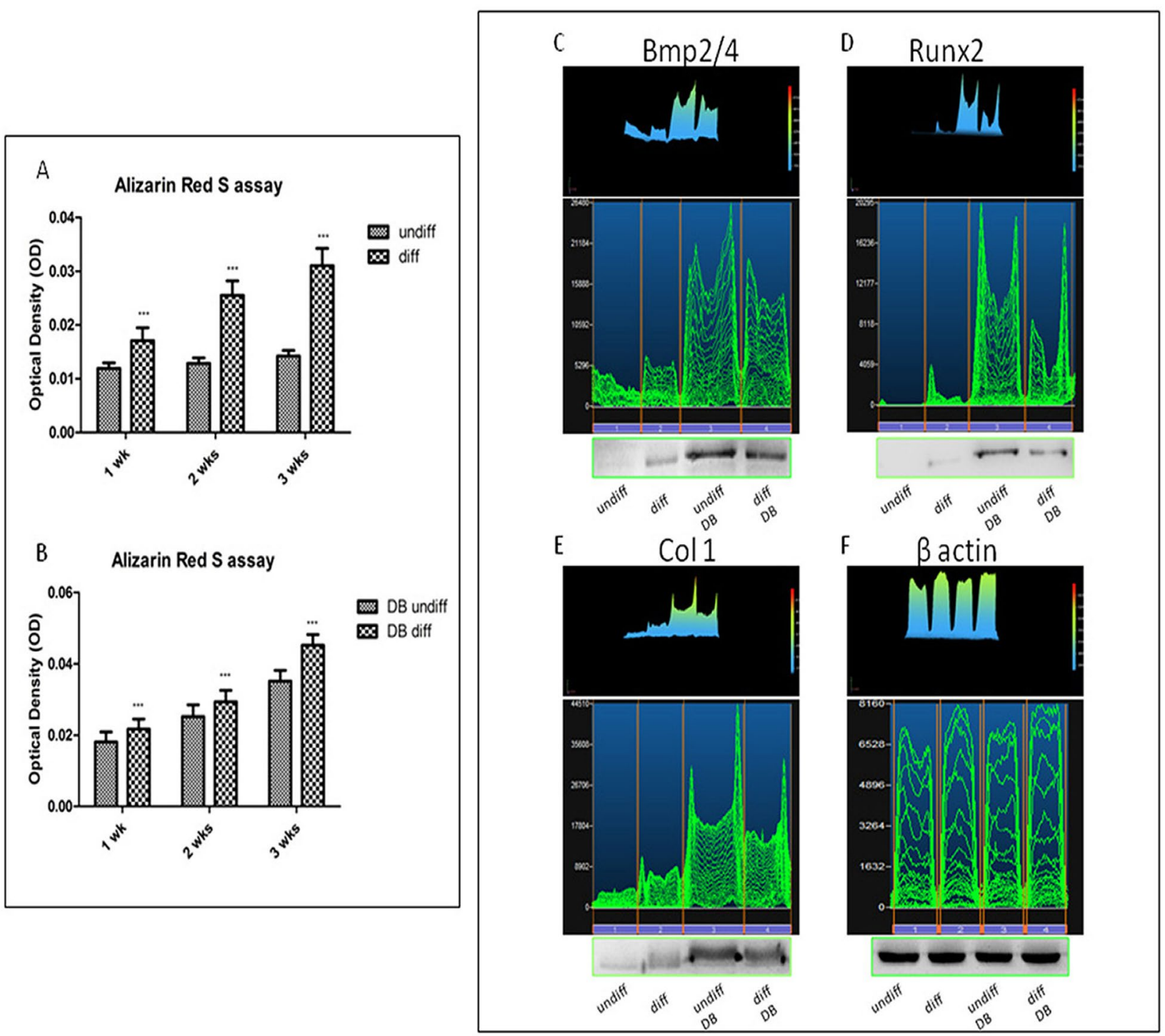

Fig. 9. Mineralisation and protein level of osteogenic related markers. The effects of the osteogenic differentiation of hPDLSCs without (A) or with DB (B) were evaluated by quantification of Alizarin red S (ARS) staining by extraction with ammonium hydroxide at different commitment time for 1, 2 and 3 weeks, in basal and osteogenic medium. Mineralisation of hPDLSCs, grown in osteogenic conditions for 1, 2 and 3 weeks, with or without biomaterial increase starting from 1 week. In basal conditions, hPDLSCs seeded on DB showed a more evident mineralisation values than the control cells placed without biomaterial. The amount of released dye was measured by a microplate reader at $405 \mathrm{~nm}$. The values, expressed as units of optical density (OD), are the mean \pm SEM of five independent experiments, in which different cell samples were used. (C) Western blotting and densitometric analysis of BMP2/4, (D) RUNX2, (E) Col 1 proteins evaluated after 1 week of culture in control and osteoinductive medium, in presence or not of biomaterial. The investigation showed an increase of osteogenic related proteins in samples induced to osteogenic differentiation and in samples grown in basal medium in presence of biomaterial. $\beta$-actin was used as housekeeping protein $(\mathbf{F})$.

Fig. 10. (On next page) Calcium channel expression and calcium measurements in hPDLSCs. qRT-PCR assay of the (A) $\alpha 1 \mathrm{C}(\mathrm{CACNA} 1 \mathrm{C})$ and (B) $\alpha 1 \mathrm{D}$ (CACNA2D1) subunits of $\mathrm{VDCC}_{\mathrm{L}}$ in hPDLSCs grown with or without DB. Stimulatory effect of the scaffold on calcium voltage channel was evident in differentiated cells and in cells grown in presence of DB. $\beta$-actin was used as internal control. Functional analysis with calcium transients. (C) The calcium transients average of all population present in well, cultured in the presence or not of biomaterial, undifferentiated or 3 weeks differentiated after $1 \mathrm{nM} \mathrm{CT}$ stimulation. (D) The calcium transients average of all population present in well, cultured in the presence or not of biomaterial, undifferentiated or 3 weeks differentiated after $20 \mathrm{nM}$ PTH stimulation. The results are the mean \pm SEM of three different experiments $(n=8)$. The statistical analysis was performed with one-way ANOVA (CT $* * * p=0.0009$; PTH $* * p=0.0097)$. (E) The percentage of 3 weeks differentiated responsive cells to stimuli (10 nM CT; $50 \mathrm{nM} \mathrm{PTH).} \mathrm{(F)} \mathrm{The} \mathrm{means} \mathrm{of} \mathrm{the} \mathrm{areas} \mathrm{under} \mathrm{curves} \mathrm{of} \mathrm{340/380} \mathrm{ratio} \mathrm{in} \mathrm{the} \mathrm{presence} \mathrm{of}$ inhibitors $(10 \mu \mathrm{g} / \mathrm{mL}$ propanolol for $\mathrm{CT}$ and $10 \mu \mathrm{M}$ TMB 8 for PTH). The statistical analysis was performed as student $t$-test (CT vs. CT + propanolol and PTH vs. PTH + TMB8; $n=9)$. $(\mathbf{E})$ and $(\mathbf{F})$ represent a typical response of calcium transient to CT $(\mathbf{G})$ or PTH $(\mathbf{H})$ in 3 weeks differentiated cells. 
A
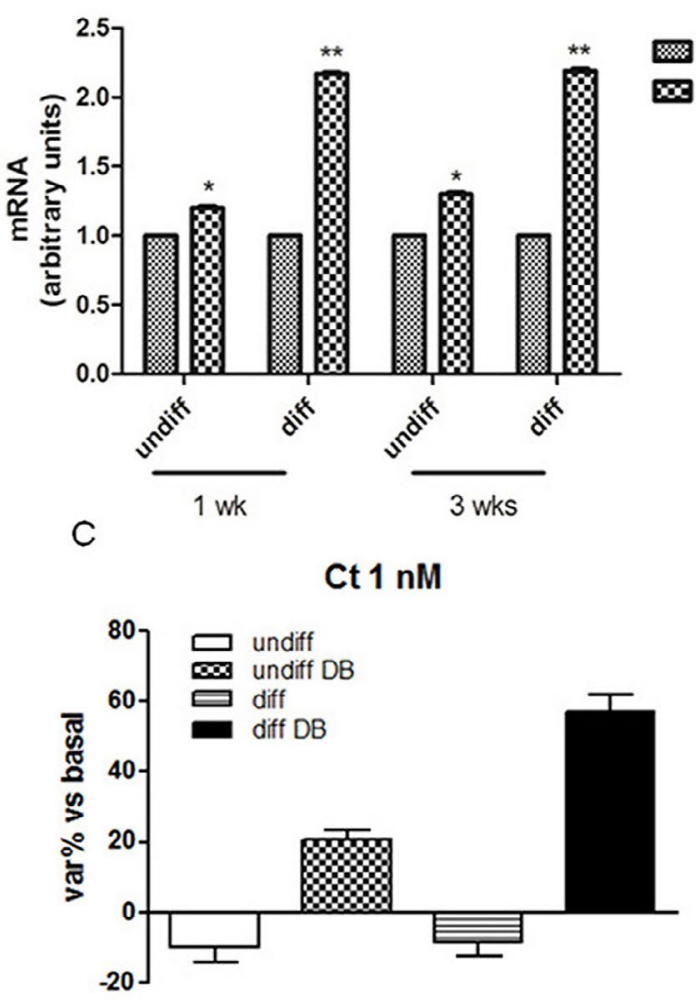

E

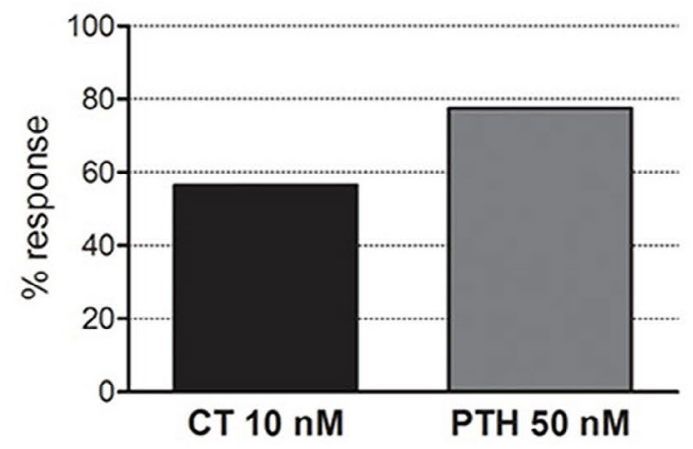

G

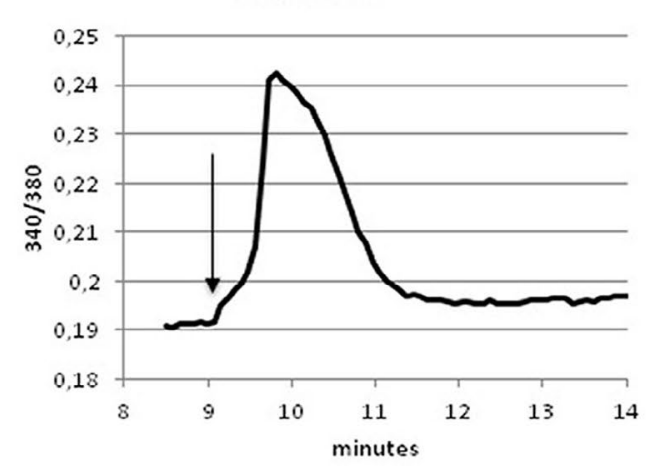

B

CACNA2D1

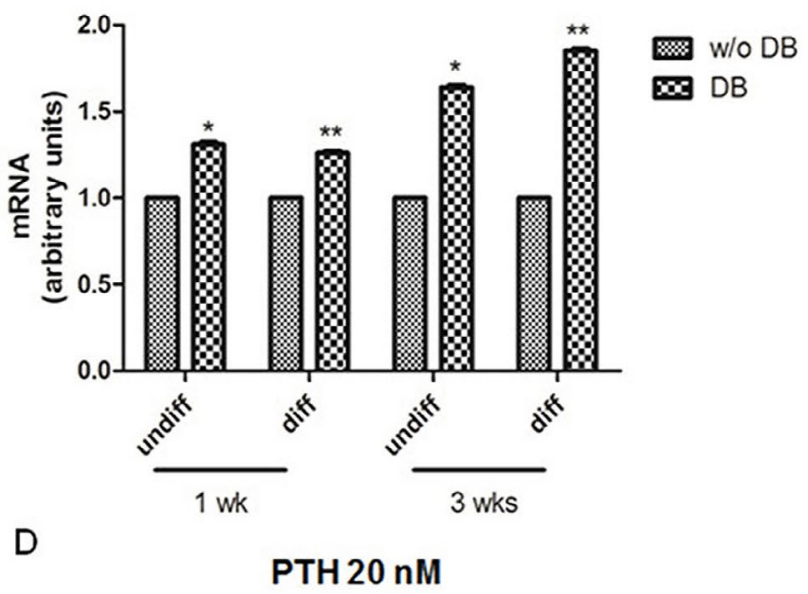

F

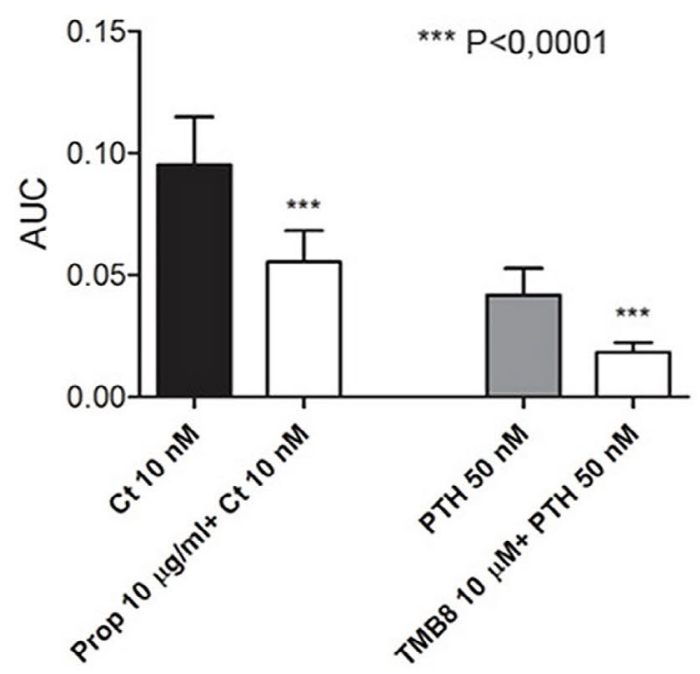

H PTH $50 \mathrm{nM}$

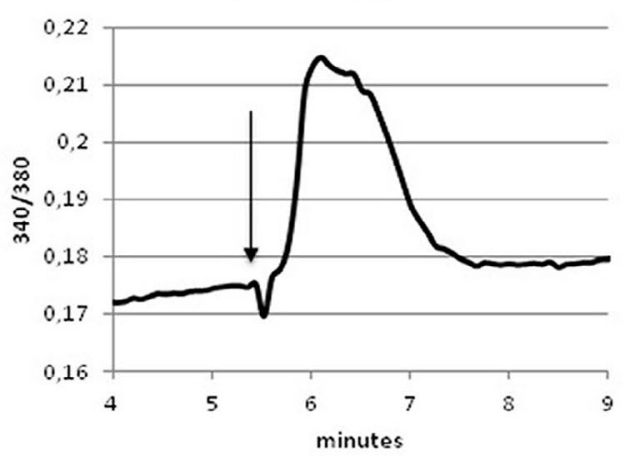

Fig. 10. Legend on previous page 

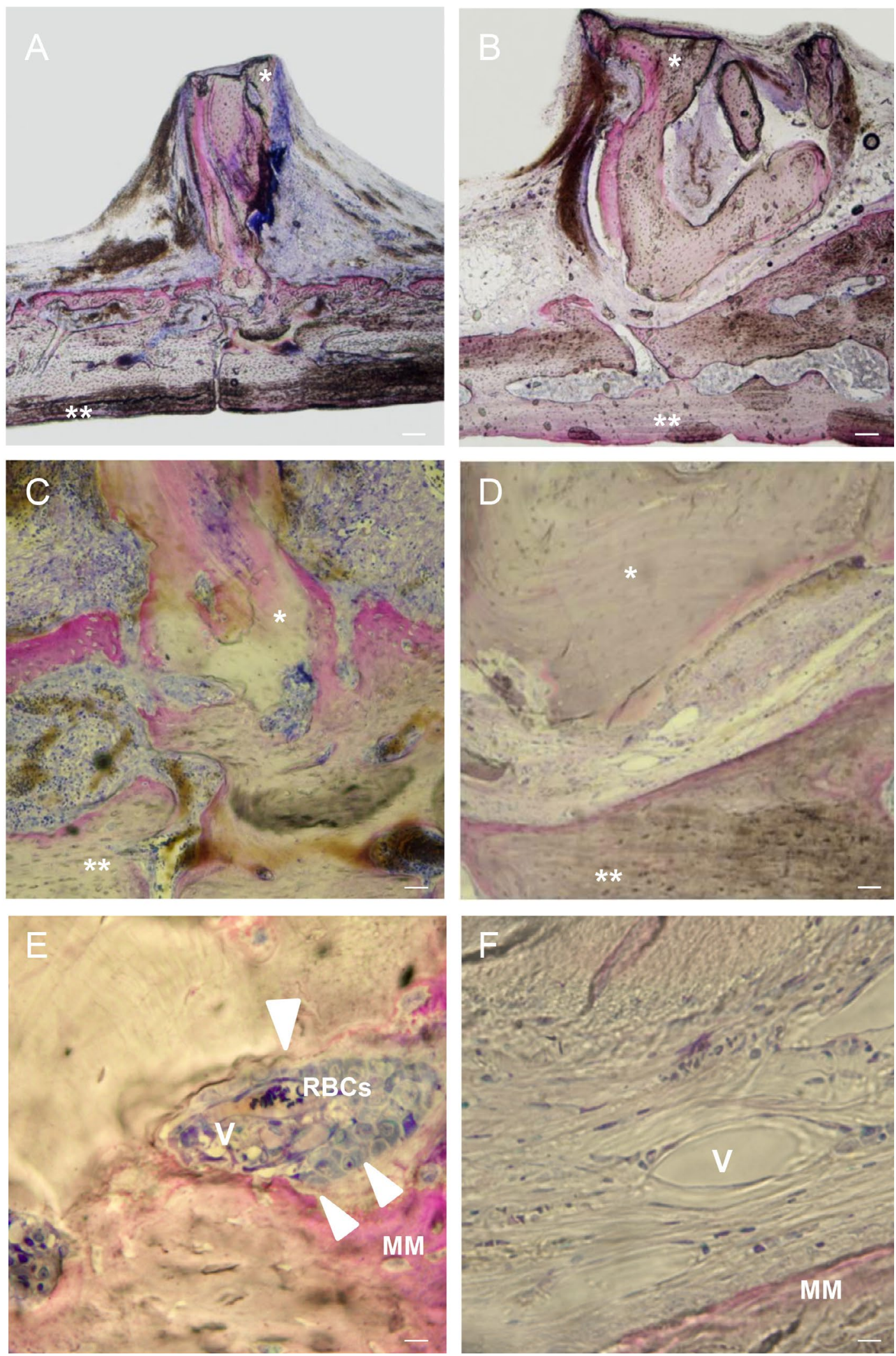

Fig. 11. Light microscopy analysis. Micrographs of acid fucsin and methylene blue stained sections. (A,C,E) Mouse calvaria with hPDLSCs/DB construct three weeks after transplantation. (B,D,F) Mouse calvaria with the scaffold without human cells three weeks after transplantation. (C) The cross section of the mouse calvaria at implant site level. After three weeks, the biomaterial in junction with the calvaria shows an evident area of integration. (E) A higher magnification of bone mouse/ DB with human cells interface. A continuous layer of cells with osteoblast-like arrangement (arrows), and mineralised matrix (MM) are present around DB. A prominent capillary invasion (V) is also present; inside vessels, red blood cells (RBCs) are clearly visible. (D,F) DB without cells promote extracellular matrix secretion and vessels demonstrating that the early stage the integration process occur. Scale bars: $10 \mu \mathrm{m}$. Original magnification: $(\mathbf{A}, \mathbf{B}) \times 2.5$; $(\mathbf{C}, \mathbf{D}) \times 10 ;(\mathbf{E}, \mathbf{F}) \times 40 . * \mathrm{DB}, * *$ mouse calvaria bone. 

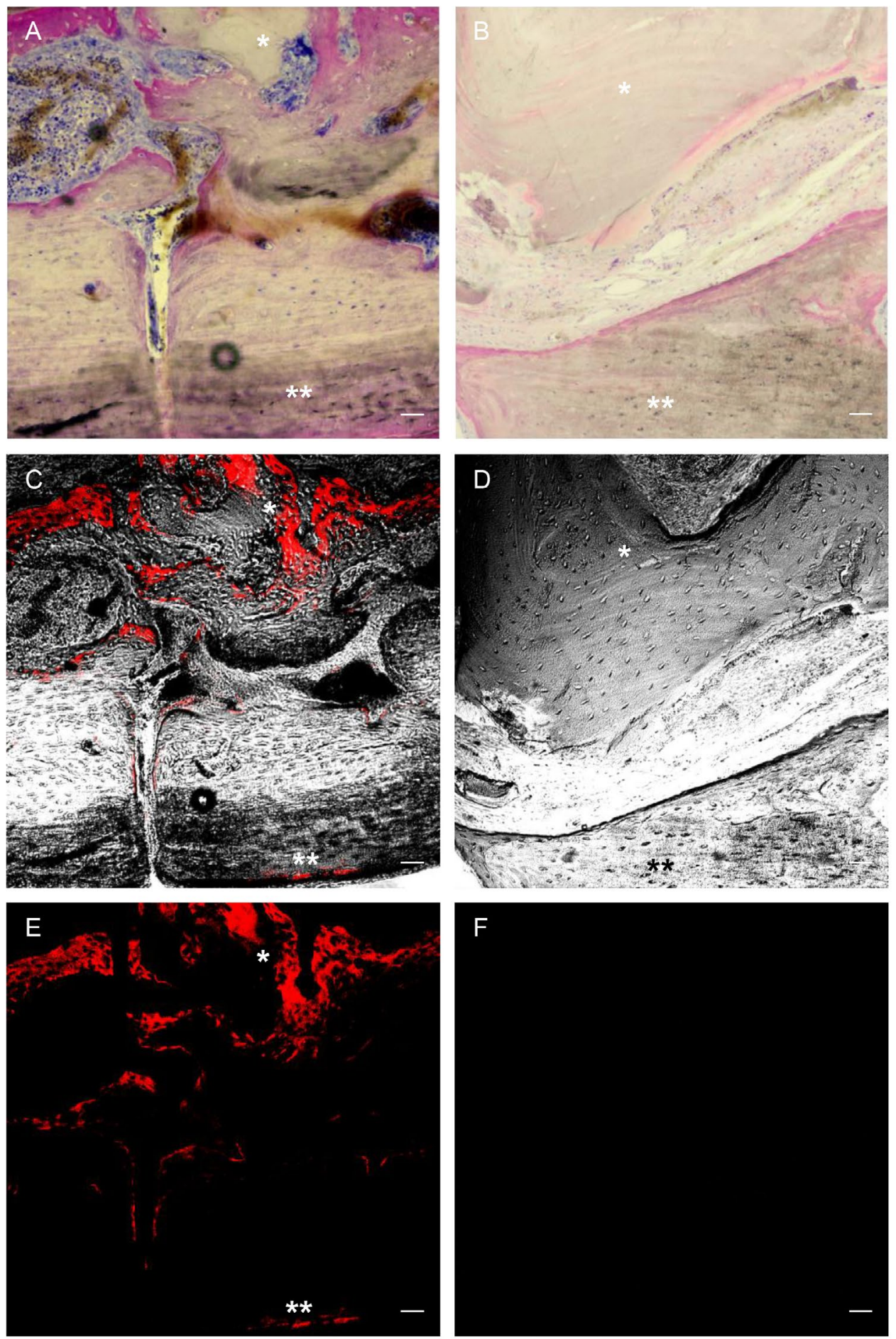

Fig. 12. Legend on next page
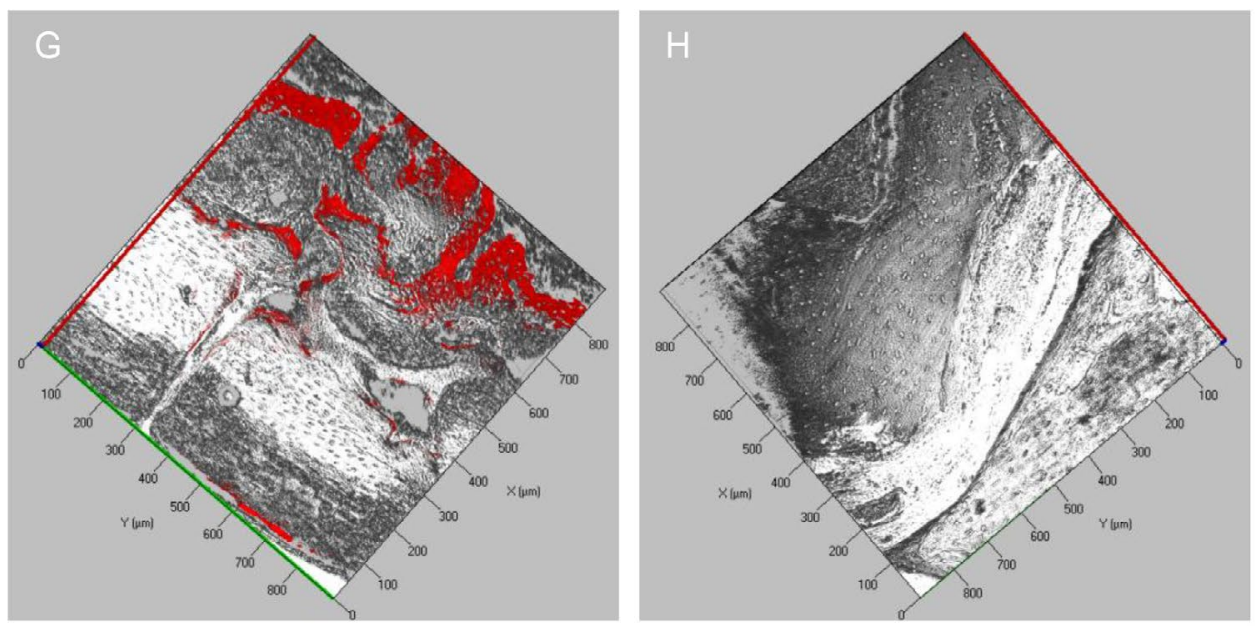
Fig. 12. (Figure on previous page) Light and confocal laser scanning microscopy analysis. Micrographs of acid fucsin and methylene blue stained section. (A,C,E,G) Three weeks after transplantation of hPDLSCs/DB scaffold in host implant site. (B,D,F,H) Three weeks after transplantation of the scaffold without cells. (C) Confocal laser scanning microscopy shows the PHK26-positive cells distributed in different zones of the implanted area. (D) DB without PHK26-positive hPDLSCs. (E,F) Single red channel to highlight the PHK26-positive cells. (G,H) Three-dimensional reconstruction of 10 slices obtained by z-stack observation through the confocal laser scanning microscopy. Scale bars: $10 \mu \mathrm{m}$. Original magnification: $\times 10$. $* \mathrm{DB}, * *$ mouse calvaria bone.

\section{Calcium channel expression and calcium measurements in hPDLSCs}

To investigate the expression pattern of L-type $\mathrm{Ca}^{2+}$ channels, in particular the $\alpha 1 \mathrm{C}$ (CACNA1C) and a2D1 (CACNA2D1) subunits in undifferentiated and differentiated hPDLSCs grown without or with the 3D scaffold we performed qRT-PCR after 1 and 3 weeks of culture. The copy number of $\alpha 1 \mathrm{C}$ was always relatively higher in the undifferentiated cells in the presence of DB when compared to the same cells in the absence of DB. The difference was much higher after 3 weeks of culture in the presence of DB and osteoinductive medium (Fig. 10A). Moreover, the gene expression level of L-Type voltagedependent $\mathrm{Ca}^{2+}$ channel $\alpha 2 \mathrm{D} 1$ subunit was also always higher in both undifferentiated and differentiated cells grown on DB compared to the same cells grown without the biomaterial (Fig. 10B). These results show that DB can present osteoinductive properties. hPDLSCs can be considered induced toward the osteogenic differentiation when they are able to respond to normal osteogenic stimuli such as calcitonin (CT) or parathormon (PTH), that regulate the bone deposition and resorption through calcium movements. Thus, to test whether a difference existed between cell cultured with or without biomaterial, we performed experimental sets in which we measured calcium transient in response to addition of CT $(1 \mathrm{nM})$ or PTH $(20 \mathrm{nM})$, in all cell populations, as variation with respect to basal value. As can be seen in Fig. 10C, at $1 \mathrm{nM}$ $\mathrm{CT}$, both the undifferentiated and 3 week differentiated cells - cultured in the presence of the biomaterial - show a significant increase with respect to basal value; in fact, in the cells cultured in the absence of biomaterial we were unable to determine an increase with respect to basal value. PTH (Fig. 10D) always determines an increase in both undifferentiated and differentiated cells with respect to basal values, though only in the presence of biomaterials is it significant. To understand how many cells in our cell population are responsive to specific stimuli in the presence of the biomaterial we have analysed the percentage of DB 3 week differentiated cells which showed a calcium increase once challenged with CT or PTH (Fig. 10E, $57 \%$ and $78 \%$, respectively). To verify if the observed transients were really provoked by hormones, we performed experiments in which CT was added to the cells in the presence of $10 \mu \mathrm{g} / \mathrm{mL}$ propranolol, a non-selective blocker of CTreceptors, already reported to counteract $\mathrm{CT}$-mediated effects (Trubiani et al., 2010). PTH was added to the cells in the presence of $10 \mathrm{nM}$ [8-(Diethylamino)octyl3,4,5-trimethoxybenzoate hydrochloride] (TMB-8), an inhibitor of the calcium release from stores widely used as an "intracellular $\mathrm{Ca}^{2+}$ antagonist" (Sugimoto et al., 1993). As it can be seen in Fig. 10F, both inhibitors significantly reduced the transients in response of CT or PTH reported, as areas under curves of the ratio (340/380). Fig. 10,G \& $\mathbf{H}$ represent a typical response of calcium transient to CT or PTH.

\section{In vivo analysis}

Adverse reactions or postoperative complications, including infection or excessive bleeding at the site of surgery, were not observed. Both hPDLSCs/DB construct and DB scaffold appeared to be intact within the defects at the time of animal sacrifice and sample collection. The image of Fig. 11A showed the mouse calvaria containing the hPDLSCs/DB construct and in Fig. 11B, the scaffold without human cells. Cross section of the explant presented evidence that, after 3 weeks, the biomaterial containing hPDLSCs was in strict contact with the calvaria and a good integration of the scaffold was evident (Fig. 11C,E). In fact, no significant difficulty in the adhesiveness process was observed, confirming the biocompatibility of the DB examined (Fig. 11D,F). Many contact zones between calvaria and hPDLSCs/DB construct could be observed. Continuous layers of differentiated hPDLSCs toward osteogenic differentiation, displaying an osteoblast-like arrangement with many osteogenic foci, were widespread within the grafted area (Fig. 11C). Extracellular matrix was deposited around DB and the calvaria, and an obvious neovascularisation with several vessels containing blood cells were present (Fig. 11E). DB without cells promoted an extracellular matrix secretion and the formation of several vessels, indicating that an integration process also occurred in this experimental condition (Fig. 11B,D,F).

Confocal laser microscopy of the calvaria slice, in the presence of hPDLSCs/DB, put in evidence a large number of PKH26 labelled hPDLSCs easily recognised by the red lipophilic dye localised at the cytoplasmic membrane level. They were largely integrated with the host tissue and distributed at the scaffold/calvaria interface and surrounded by the newly deposited matrix under osteogenic commitment (Fig.12C,E). Fig. 12 D,F showed the absence of red signal in the sample without cells. Three-dimensional reconstructions of 10 slices, obtained by z-stack observation through the confocal laser scanning microscopy, are shown in Fig. 12G,H.

\section{Discussion}

Bone reconstruction often needs large volumes of donor tissue. In orthopaedics and the maxillofacial region, complex surgical procedures are necessary to obtain functional and aesthetic results to improve quality of life after injury or tumour resection. 
The development of new strategies able to be involved in the production of biocompatible matrices that will replace the native tissue, without causing necrosis or scar formation, is a stimulating area of research. To produce an appropriate construct, for in vivo use, different steps are needed: (i) tissue biopsy, (ii) in vitro cells isolation and expansion, and (iii) building up the cell-construct with an appropriate 3-D biomaterial (Temenoff and Mikos, 2000).

Starting from these paradigms, in this paper we present a new bone graft obtained using xeno-free hPDLSCs, isolated from periodontium biopsy, seeded on corticocancellous DB scaffold. Periodontal ligament has the capacity to act as a sensory receptor necessary for the proper positioning of the jaws during mastication and, very importantly, it is a cell reservoir for tissue homeostasis and for regenerative medicine (Nanci and Bosshardt, 2006; Trubiani et al., 2010). Clinical applications of cell therapy represent a complex challenge, for the necessity of operating under strict Good Manufacturing Procedure, and for the absolute need to demonstrate not just the safety of the proposed approach but, first and foremost, its feasibility, without compromising the safety of the patients, and an acceptable degree of reproducibility for clinical application (Banfi et al., 2000; Salvade et al., 2007; Trubiani et al., 2015).

Even if many efforts have shown that human placenta, bone marrow, and skin stem cells (Chase et al., 2010) can be isolated and expanded in serum free medium, recently we published a culture system for the expansion and production of hPDLSCs using a new xeno-free media formulation ensuring the maintenance of the stem cells features comprising: the multiple passage expansion, mesengenic lineage differentiation, cellular phenotype and genomic stability, all essential elements for conforming to translation to cell therapy.

Three dimensional scaffolds are biocompatible structures which can simulate the ECM properties, such as mechanical support, cellular activity and protein production through biochemical and mechanical interactions, and can be a template for cell attachment and stimulation for bone tissue formation in vivo (Amini et al., 2011; Dimitriou et al., 2011; Soucacos et al., 2008). Scaffold's performance is related to chemistry, pore size, pore volume and mechanical strength. At an early stage, bone ingrowth happens at the periphery of scaffolds with a negative gradient in mineralisation toward the inner parts (Baroli, 2009). For continuous ingrowth of bone tissue, interconnected porosity is essential, indeed open and interconnected pores allow nutrients and molecules to be transported into the inner parts of a scaffold to facilitate cell proliferation and vascularisation. Thus, based on these considerations the osteo-cancellous geometry of 3D-DB scaffold could represent an ideal biomaterial in tissue regeneration.

Indeed, MTT analysis carried out at different time points on hPDLSCs showed a logarithmic cell proliferation in control samples comparable to cells seeded on DB scaffold, indicating that the biomaterial does not interfere with cell growth.

Transmission electron microscopy analysis showed that the scaffold has been colonised by hPDLSCs and demonstrated the presence of extracellular matrix production in control and treated samples in the presence of DB scaffold. Furthermore, after 1 week, some hPDLSCs cultured in presence of DB showed ovoid shape with short elongations. Samples induced to osteogenic differentiation in the presence of DB showed the ECM organised in cross-banded fibrils and junctional-like contacts between neighbouring cells indicating a preosteoblast pseudoepithelial arrangement. This indicates a clearly more differentiated phenotype suggesting that $\mathrm{DB}$, for its ability to support hPDLSCs growth and differentiation, could be a suitable carrier for bone tissue reconstruction. Bone formation involves the proliferation and differentiation of stromal cells along an osteogenic pathway that leads to the formation of osteoblasts; it is believed that the process of cellular differentiation is controlled by a cascade of molecular events involving a combination of genetic programming and gene regulation by hormones, cytokines, and bone associated-molecules (Sodek and McKee, 2000).

Quantitative Real-Time PCR, carried out at 1 and 3 weeks in differentiated and undifferentiated hPDLSCs in the presence of the $\mathrm{DB}$, revealed a significant modulation of osteogenesis-associated genes. Interestingly, the scaffold seems to have a specific role in osteogenic induction of the undifferentiated hPDLSCs activating RUNX2, BMP family members (BMP2, 3, 4, 6) and many collagens genes (COL1A1, COL3A1, COL10A1, COL12A1, COL14A1, COL16A1, COL18A1). RUNX2 is the most important transcription factor in bone formation (Greenblatt et al., 2013). Bone Morphogenic Proteins (BMPs) are the major bone morphogens by regulating cell condensation, as well as inducing chondrogenesis and osteogenesis (Minear et al., 2010; Trubiani et al., 2010; Wu et al., 2007). Collagens deposition is a clear signal of an active osteogenesis, being that collagens are essential for bone tissue formation and functions (Reddi, 2000) and it has been reported that biomaterials could improve osteogenesis and collagens deposition (Holzwarth and Ma, 2011). Given the role of BMP2/4, RUNX2 and Collagen1A1 as important markers in the osteogenic process, their up-regulation has been also validated through the western blotting analysis thus strengthening the evidence of an osteoinductive activity at precocious time of culture in presence of the 3D-scaffold.

To further support the evidence that hPDLSCs cultured on DB were induced to differentiate towards a functional osteoblast lineage, the cells were stimulated with two physiological molecules, namely Parathyroid hormone (PTH) and Calcitonin (CT). Parathyroid hormone is a well known regulator of calcium homeostasis and represents a key mediator in processes such as bone metabolism (Qin et al., 2004) and consequently skeletal development and remodelling. Receptors for PTH, are reported to activate several intracellular signalling pathways, including intracellular $\mathrm{Ca}^{2+}$ increase and to be functionally expressed in osteoblastic lineage, beginning from very early stage of cell maturation to terminally differentiated cells (Candeliere et al., 2001). Also, the receptor for calcitonin (CTR), coupled to the adenylyl cyclase-protein kinase A pathway and the phospholipase $C$, with subsequent calcium mobilisation and activation of protein kinase $\mathrm{C}$, has been detected in osteoblasts. The hormone has also been shown to induce a significant increase in $[3 \mathrm{H}]-$ 
thymidine incorporation and PKC activity in human osteoblast cultures, with a maximal effect, at $10^{-10} \mathrm{M}$ (Villa et al., 2003). In fact, we demonstrated that CT, also at low concentration $(1 \mathrm{nM})$, is able to determine an increase of intracellular calcium in all population.

Both the hormones were able to trigger a functional response in our cells grown onto DB. Intracellular calcium increase, which is involved in several biological processes, is known to be caused not only by G-protein coupled receptor activation, but also by the gating of membrane surface calcium channels including voltage dependent calcium channels $\left(\mathrm{VDCC}_{\mathrm{L}}\right) . \mathrm{VDCC}_{\mathrm{L}}$ are expressed not only in almost all excitable cells but also in non-excitable ones, including proliferating osteoblasts, where they exert a crucial role in modulating gene expression of bone matrix proteins, in supporting the signal-secretion coupling and in regulating the response to mechanical stimuli which in turn control bone density (Chen et al., 2000). These channels are composed by the main subunit $\alpha 1$ which is the pore-forming one and by other subunits $\delta$, $\beta$ and $\gamma$, with an auxiliary activity. The association of the $\alpha 1$ subunit with $\alpha 2 \mathrm{D}$ ones has been shown to potentiate the gating properties of the channel. In osteoblasts the $\gamma$ subunit is lacking and $\alpha 2 \mathrm{D} 1$, but not $\alpha 2 \mathrm{D} 2$, has been reported to be expressed (Bergh et al., 2006). In the present study, by using qRT-PCR, we found that both $\alpha 1 \mathrm{C}$ and $\alpha 2 \mathrm{D} 1 \mathrm{VDCC}_{\mathrm{L}}$ subunits are also expressed in hPDLSCs under undifferentiated condition and that the expression significantly increased in the presence of DB. This further supports the hypothesis that the DB drives the cells towards osteogenic differentiation. This result, together with the response at low CT concentration in all population, suggests that our cultures are heterogeneous, with cells probably in several differentiation states.

In vivo models, to test biomaterials and living constructs, play an important role in determining the tissue regeneration potential of such devices. Most studies have been carried out using autologous cells or immunocompromised animals. To our knowledge, we report for the first time results obtained using stem cells derived from human periodontal ligament implanted in non-immunocompromised mice. The lacking host-versusgraft reaction at the grafted site could be linked, as already reported, to the evidence that stem cells from periodontal ligament and dental pulp possess immunosuppressive properties (Trubiani et al., 2008a).

Our results indicate that the periodontal ligament stem cells implanted in mouse do not show immunogenic effects and after 3 weeks a massive number of cells, with different size and features, were detected in the mouse calvaria implanted with hPDLSCs/DB construct. Extracellular matrix secretion during mineralisation and differentiated cells organised as epithelial like layer, essential elements for bone mineralisation, can be observed. Our experiments also demonstrate an extensive perfusable vascular network. On the contrary, DB implanted on host site showed the presence of cell with fibroblast-like morphology and vessels indicating the early stage of osteointegration. This scenario offers the opportunity to speculate that the presence of hPDLSCs could exert a beneficial regenerative influence for the following considerations: i) to contribute directly to osteogenesis, ii) to activate a local angiogenic response, iii) to home the host stem cells improving the regeneration potential trough a paracrine effect inducing the endogenous mouse MSCs to migrate toward the implant site. In fact hPDLSCs release high level of SDF-1 in the culture medium (Trubiani et al., 2008a) and SDF-1 often acts as a potent chemoattractant to recruit circulating or resident CXCR4-expressing MSCs, which are necessary for specific tissue or organ repair (Zhu et al., 2015). Then, the presence of living cells linked to the DB can be suggestive of a more rapid evolution and a major degree of maturation in bone tissue regeneration.

\section{Conclusions}

In synthesis, the highly efficient cell proliferation, together with osteogenic and vascular differentiation and functional response, make the living construct composed by xeno-free hPDLSCs/3D porcine DB an innovative biocompatible system potentially useful in the reconstructing of skeletal segmental defects in tissue engineering.

\section{Acknowledgements}

This work has been supported from OT ex $60 \%$ University of Chieti fund, and partly by PRIN 20102ZLNJ5 "Stem cells and 3D scaffolds: a novel construct in bone regeneration" financed by the Ministry of Education, University and Research (M.I.U.R.), Rome, Italy.

\section{References}

Amini AR, Wallace JS, Nukavarapu SP (2011) Shortterm and long-term effects of orthopedic biodegradable implants. J Long Term Eff Med Implants 21: 93-122.

Banfi A, Muraglia A, Dozin B, Mastrogiacomo M, Cancedda R, Quarto R (2000) Proliferation kinetics and differentiation potential of ex vivo expanded human bone marrow stromal cells: Implications for their use in cell therapy. Exp Hematol 28: 707-715.

Baroli B (2009) From natural bone grafts to tissue engineering therapeutics: Brainstorming on pharmaceutical formulative requirements and challenges. J Pharm Sci 98: 1317-1375.

Bergh JJ, Shao Y, Puente E, Duncan RL, FarachCarson MC (2006) Osteoblast $\mathrm{Ca}(2+)$ permeability and voltage-sensitive $\mathrm{Ca}(2+)$ channel expression is temporally regulated by 1,25-dihydroxyvitamin $\mathrm{D}(3)$. Am J Physiol Cell Physiol 290: C822-C831.

Candeliere GA, Liu F, Aubin JE (2001) Individual osteoblasts in the developing calvaria express different gene repertoires. Bone 28: 351-361.

Carranza FA (1996) In: Clinical Periodontology, (Newman F, ed), W.B. Saunders, Philadelphia, pp 31-50.

Chase LG, Lakshmipathy U, Solchaga LA, Rao MS, Vemuri MC (2010) A novel serum-free medium for the 
expansion of human mesenchymal stem cells. Stem Cell Res Ther 1: 8. DOI: $10.1186 /$ scrt8.

Chen NX, Ryder KD, Pavalko FM, Turner CH, Burr DB, Qiu J, Duncan RL (2000) Ca(2+) regulates fluid shearinduced cytoskeletal reorganization and gene expression in osteoblasts. Am J Physiol Cell Physiol 278: C989-C997.

Diomede F, Caputi S, Merciaro I, Frisone S, D'Arcangelo C, Piattelli A, Trubiani O (2014) Proinflammatory cytokine release and cell growth inhibition in primary human oral cells after exposure to endodontic sealer. Int Endod J 47: 864-872.

Dimitriou R, Jones E, McGonagle D, Giannoudis PV (2011) Bone regeneration: current concepts and future directions. BMC Med 9: 66.

Egusa H, Sonoyama W, Nishimura M, Atsuta I, Akiyama K (2012) Stem cells in dentistry--part I: stem cell sources. J Prosthodont Res 56: 151-165.

Eleuterio E, Trubiani O, Sulpizio M, Di Giuseppe F, Pierdomenico L, Marchisio M, Giancola R, Giammaria G, Miscia S, Caputi S, Di Ilio C, Angelucci S. (2013) Proteome of human stem cells from periodontal ligament and dental pulp. PloS One 8: e71101.

Greenblatt MB, Shim JH, Glimcher LH (2013) Mitogen-activated protein kinase pathways in osteoblasts. Annu Rev Cell Dev Biol 29: 63-79.

Gregory CA, Gunn WG, Peister A, Prockop DJ (2004) An Alizarin red-based assay of mineralization by adherent cells in culture: comparison with cetylpyridinium chloride extraction. Anal Biochem 329: 77-84.

Holzwarth JM, Ma PX (2011) Biomimetic nanofibrous scaffolds for bone tissue engineering. Biomaterials 32: 9622-9629.

Manescu A, Giuliani A, Mohammadi S, Tromba G, Mazzoni S, Diomede F, Zini N, Piattelli A, Trubiani O (2016) Osteogenic potential of dualblocks cultured with human periodontal ligament stem cells: in vitro and synchrotron microtomography study. J Periodontal Res 51: 112-124.

Minear S, Leucht P, Miller S, Helms JA (2010) rBMP represses Wnt signaling and influences skeletal progenitor cell fate specification during bone repair. J Bone Miner Res 25: 1196-1207.

Nanci A, Bosshardt DD (2006) Structure of periodontal tissues in health and disease. Periodontol 2000 40: 11-28.

Qin L, Raggatt LJ, Partridge NC (2004) Parathyroid hormone: a double-edged sword for bone metabolism. Trends Endocrinol Metab 15: 60-65.

Reddi AH (2000) Morphogenesis and tissue engineering of bone and cartilage: inductive signals, stem cells, and biomimetic biomaterials. Tissue Eng 6: 351-359.

Rose FR, Oreffo RO (2002) Bone tissue engineering: hope vs. hype. Biochem Biophys Res Commun 292: 1-7.

Salvade A, Belotti D, Donzelli E, D’Amico G, Gaipa G, Renoldi G, Carini F, Baldoni M, Pogliani E, Tredici G, Biondi A, Biagi E (2007) GMP-grade preparation of biomimetic scaffolds with osteo-differentiated autologous mesenchymal stromal cells for the treatment of alveolar bone resorption in periodontal disease. Cytotherapy 9: 427-438.
Seo BM, Miura M, Sonoyama W, Coppe C, Stanyon R, Shi S (2005) Recovery of stem cells from cryopreserved periodontal ligament. J Dent Res 84: 907-912.

Sodek J, McKee MD (2000) Molecular and cellular biology of alveolar bone. Periodontol 2000 24: 99-126.

Soucacos PN, Johnson EO, Babis G (2008) An update on recent advances in bone regeneration. Injury 39 Suppl 2: S1-4.

Sugimoto T, Kano J, Yamaguchi T, Fukase M, Chihara K (1993) Role of calcium/protein kinase $C$ in the regulation of DNA synthesis by parathyroid hormone-related peptide in osteoblastic osteosarcoma cells. Horm Metab Res 25: 608-611.

Temenoff JS, Mikos AG (2000) Review: tissue engineering for regeneration of articular cartilage. Biomaterials 21: 431-440.

Trubiani O, Fulle S, Traini T, Paludi M, la Rovere R, Orciani M, Caputi S, Piattelli A (2010) Functional assay, expression of growth factors and proteins modulating bonearrangement in human osteoblasts seeded on an anorganic bovine bone biomaterial. Eur Cell Mater 20: 72-83.

Trubiani O, Giacoppo S, Ballerini P, Diomede F, Piattelli A, Bramanti P, Mazzon E. (2016a) Alternative source of stem cells derived from human periodontal ligament: a new treatment for experimental autoimmune encephalomyelitis. Stem Cell Res Ther 7: 1.

Trubiani O, Guarnieri S, Diomede F, Mariggiò MA, Merciaro I, Morabito C, Cavalcanti MF, Cocco L, Ramazzotti G (2016b) Nuclear translocation of PKCalpha isoenzyme is involved in neurogenic commitment of human neural crest-derived periodontal ligament stem cells. Cell Signal 28: 1631-1641.

Trubiani O, Isgro A, Zini N, Antonucci I, Aiuti F, Di Primio R, Nanci A, Caputi S, Paganelli R (2008a) Functional interleukin-7/interleukin-7Ralpha, and SDF1alpha/CXCR4 are expressed by human periodontal ligament derived mesenchymal stem cells. J Cell Physiol 214: 706-713.

Trubiani O, Orsini G, Zini N, Di Iorio D, Piccirilli M, Piattelli A, Caputi S (2008b) Regenerative potential of human periodontal ligament derived stem cells on three-dimensional biomaterials: a morphological report. J Biomed Mater Res A 87: 986-993.

Trubiani O, Piattelli A, Gatta V, Marchisio M, Diomede F, D'Aurora M, Merciaro I, Pierdomenico L, Maraldi NM, Zini N (2015) Assessment of an efficient xeno-free culture system of human periodontal ligament stem cells. Tissue Eng Part C Methods 21: 52-64.

Villa I, Dal Fiume C, Maestroni A, Rubinacci A, Ravasi F, Guidobono F (2003) Human osteoblast-like cell proliferation induced by calcitonin-related peptides involves PKC activity. Am J Physiol Endocrinol Metab 284: E627-E633.

Wu X, Shi W, Cao X (2007) Multiplicity of BMP signaling in skeletal development. Ann N Y Acad Sci 1116: 29-49.

Zhu W, Zhang Q, Zhang Y, Cen L, Wang J (2015) PDL regeneration via cell homing in delayed replantation of avulsed teeth. J Transl Med 13: 357. 
Zwingenberger S, Yao Z, Jacobi A, Vater C, Valladares RD, Li C, Nich C, Rao AJ, Christman JE, Antonios JK, Gibon E, Schambach A, Maetzig T, Goodman SB, Stiehler M (2014) Enhancement of BMP-2 induced bone regeneration by SDF-1alpha mediated stem cell recruitment. Tissue Eng Part A 20: 810-818.

\section{Discussion with Reviewer}

Petros Papagerakis: How far is this research from clinical applications?

Authors: This research putting in evidence through multiparametric analysis of the behaviour of the cells in presence of biomaterial, either in vitro or in vivo, open the actual prospects for the application in regenerative medicine. For this reason we believe that it is really close to the use in clinical applications.

Petros Papagerakis: What are the next steps towards a clinical trial?

Authors: The first step for clinical application is the technological transfer of the "in vitro" periodontal ligament stem cells culture protocol in cGMP condition. Our laboratory is already cooperating with an authorised Italian cell factory to validate the expansion cells culture protocol reported in this paper in cGMP conditions.

Editor's note: The Scientific Editor responsible for this paper was Thimios Mitsiadis. 